\title{
Investigating the potential use of Sentinel-1 data for monitoring wetland water level changes in China's Momoge National Nature Reserve
}

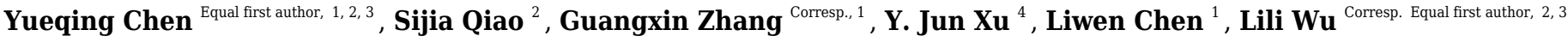 \\ ${ }^{1}$ Northeast Institute of Geography and Agroecology, Chinese Academy of Sciences, Changchun, Jilin, China \\ 2 School of Geographic Sciences, Xinyang Normal University, Xinyang, Henan, China \\ ${ }^{3}$ Key Laboratory for Synergistic Prevention of Water and Soil Environmental Pollution, Xinyang Normal University, Xinyang, Henan, China \\ 4 School of Renewable Natural Resources, Louisiana State University Agricultural Center, Baton Rouge, America \\ Corresponding Authors: Guangxin Zhang, Lili Wu \\ Email address: zhgx@iga.ac.cn, wulili@iga.ac.cn
}

Background. Interferometric Synthetic Aperture Radar (InSAR) has become a promising technique for monitoring wetland water levels. However, its capability in monitoring wetland water level changes with Sentine-1 data has not yet been thoroughly investigated. Methods. In this study, we produced a multitemporal Sentinel-1 C-band VV-polarized SAR backscatter images and generated a total of 28 interferometric coherence maps for marsh wetlands of China's Momoge National Nature Reserve to investigate the interferometric coherence level of Sentinel-1 C-VV data as a function of perpendicular and temporal baseline, water depth, and SAR backscattering intensity. We also selected six interferogram pairs acquired within 24 days for quantitative analysis of the accuracy of water level changes monitored by Sentinel-1 InSAR. The accuracy of water level changes determined through the Sentinel-1 InSAR technique was calibrated by the values of six field water level loggers. Results. Our study showed: (1) the coherence was mainly dependent on the temporal baseline and was little affected by the perpendicular baseline for Sentinel-1 C-VV data in marsh wetlands; (2) in the early stage of a growing season, a clear negative correlation was found between Sentinel-1 coherence and water depth; (3) there was an almost linear negative correlation between Sentinel-1 C-VV coherence and backscatter for the marsh wetlands; (4) once the coherence exceeds a threshold of 0.3, the stage during the growing season, rather than the coherence, appeared to be the primary factor determining the quality of the interferogram for the marsh wetlands, even though the quality of the interferogram largely depends on the coherence; (5) The results of water level changes from InSAR processing show no agreement with in-situ measurements during most growth stages. Based on the findings, we can conclude that although the interferometric coherence of the Sentinel-1 C-VV data is high enough, the 
data is generally unsuitable for monitoring water level changes in marsh wetlands of China's Momoge National Nature Reserve. 


\section{Investigating the potential use of Sentinel-1 data for}

\section{2 monitoring wetland water level changes in China's Momoge}

\section{National Nature Reserve}

4 Yueqing Chen Equal first author, 1, 2, 3, Sijia Qiao ${ }^{2}$, Guangxin Zhang Corresp., 1, Y. Jun Xu ${ }^{4}$, Liwen Chen

5 , Lili Wu Corresp., Equal first author, 2, 3

$6{ }^{1}$ Northeast Institute of Geography and Agroecology, Chinese Academy of Sciences, Changchun,

7 Jilin, China

$8{ }^{2}$ School of Geographic Sciences, Xinyang Normal University, Xinyang, Henan, China

$9{ }^{3}$ Key Laboratory for Synergistic Prevention of Water and Soil Environmental Pollution,

10 Xinyang Normal University, Xinyang, Henan, China

$11{ }^{4}$ School of Renewable Natural Resources, Louisiana State University Agricultural Center, Baton

12 Rouge, America

13 Corresponding Author: Guangxin Zhang; Lili Wu

14 Equal First Author: Yueqing Chen; Lili Wu

15 E-mail address: chenyueqing@iga.ac.cn (Yueqing Chen); qiaosijia@xynu.edu.cn (Sijia Qiao);

16 zhgx@iga.ac.cn (Guangxin Zhang); yjxu@1su.edu (Y. Jun Xu); chenliwen86@126.com (Liwen

17 Chen); wulili@iga.ac.cn (Lili Wu)

18 Received: date; Accepted: date; Published: date

19 Abstract

20 Background. Interferometric Synthetic Aperture Radar (InSAR) has become a promising

21 technique for monitoring wetland water levels. However, its capability in monitoring wetland

22 water level changes with Sentine-1 data has not yet been thoroughly investigated. Methods. In

23 this study, we produced a multitemporal Sentinel-1 C-band VV-polarized SAR backscatter

24 images and generated a total of 28 interferometric coherence maps for marsh wetlands of China's

25 Momoge National Nature Reserve to investigate the interferometric coherence level of Sentinel-

$261 \mathrm{C}-\mathrm{VV}$ data as a function of perpendicular and temporal baseline, water depth, and SAR

27 backscattering intensity. We also selected six interferogram pairs acquired within 24 days for 
28 quantitative analysis of the accuracy of water level changes monitored by Sentinel-1 InSAR. The 29 accuracy of water level changes determined through the Sentinel-1 InSAR technique was calibrated by the values of six field water level loggers. Results. Our study showed: (1) the coherence was mainly dependent on the temporal baseline and was little affected by the perpendicular baseline for Sentinel-1 C-VV data in marsh wetlands; (2) in the early stage of a growing season, a clear negative correlation was found between Sentinel-1 coherence and water depth; (3) there was an almost linear negative correlation between Sentinel-1 C-VV coherence and backscatter for the marsh wetlands; (4) once the coherence exceeds a threshold of 0.3 , the stage during the growing season, rather than the coherence, appeared to be the primary factor determining the quality of the interferogram for the marsh wetlands, even though the quality of the interferogram largely depends on the coherence; (5) The results of water level changes from InSAR processing show no agreement with in-situ measurements during most growth stages. Based on the findings, we can conclude that although the interferometric coherence of the Sentinel-1 C-VV data is high enough, the data is generally unsuitable for monitoring water level changes in marsh wetlands of China's Momoge National Nature Reserve.

\section{Introduction}

Covering between 1-2\% of the Earth's surface, wetlands are among the most productive ecological systems and perform important eco-hydrological functions such as food supply, water storage and purification, flood control, climate change mitigation, as well as provide a desirable habitat for wildlife (Millenium Ecosystem Assessment 2005; Costanza et al. 1997; Mitsch \& Gosselink 2015). Unfortunately, according to the latest IPBES assessment report (Scholes et al. 2018), wetlands are particularly degraded, with $87 \%$ lost globally in the last 300 years, and 54\% since 1900. It is widely recognized that wetlands play an important role in the hydrological cycle, and vice versa, the hydrological conditions have a crucial impact on the development and degradation of wetlands (Cole et al. 1997; Hunt et al. 1999; Mitsch \& Gosselink 2015).

Therefore, the conservation and restoration of wetlands requires more specific information about their hydrological conditions. Typically, hydrological monitoring of wetlands is carried out through stage (water level) stations providing good temporal resolution over a finite number of observation points (Hong et al. 2010a). However, these in-situ measurements have limited capability to detect spatial patterns, as gauge stations are usually located several or even tens of kilometers from each another (Hong et al. 2010a; Wdowinski \& Hong 2015). 
59

60

61

62

63

64

65

66

67

68

69

70

Wetland InSAR technique can be an excellent complementary tool for in-situ ground observations to better understand and monitor a wide area with high spatial resolution (Hong \& Wdowinski 2017). Since the first time Alsdorf et al. (2000) and Alsdorf et al. (2001) mapped a spatial detailed image of centimeter-scale variations in the Amazon floodplain water level response to changing river discharge through InSAR, innovative applications of InSAR to monitoring hydrologic changes in wetlands have also been successful in different regions of the world (Kim et al. 2014), including but not limited to the Everglades (Hong et al. 2010a; Kim et al. 2014; Liao \& Wdowinski 2018; Wdowinski et al. 2004; Wdowinski et al. 2008), the Louisiana wetlands (Kim et al. 2009; Kwoun \& Lu 2009; Lu et al. 2005), the Amazon floodplain (Cao et al. 2018), the Sian Ka'an in Yucatan (Gondwe et al. 2010), the Yellow River Delta (Xie et al. 2013; Xie et al. 2015; Yuan et al. 2016), the Liaohe River (Zhang et al. 2016), the Great Dismal Swamp (Kim et al. 2017), the Ciénaga Grande de Santa Marta (Jaramillo et al. 2018), the Yukon Flats Basin (Pitcher et al. 2019) and, most recently, the Peace-Athabasca Delta (Siles et al. 2020). Today, wetland InSAR technique has evolved from monitoring relative water level changes to monitoring absolute water level time series. However, using the InSAR technique for monitoring wetland water level is still a relatively new research field that has not yet been fully exploited (Mohammadimanesh et al. 2018b), especially for many developing and undeveloped countries.

Radar signal backscattering mechanisms can be simplified into four major categories: double bounce scattering, surface scattering, volume scattering, and specular scattering (Kwoun \& Lu 2009). The wetland InSAR technique works where vegetation emerges above the water surface owing to the double bounce effect, in which the radar signal is backscattered twice from the water surface and vegetation (Richards et al. 1987). Three main sources of losing interferometric coherence, i.e., geometric, volumetric and temporal decorrelations, are integrated and determine the portion of the SAR signal that is available to produce double bounce backscattering over wetlands (Lu \& Kwoun 2008). Furthermore, different wetland classes such as marsh, swamp, bog, fen, and shallow water have different backscattering behavior depending on SAR satellites wavelength, polarization, incidence angle, spatial resolution, environmental variables, and wetland phenology (Mohammadimanesh et al. 2018b). To date, a number of studies have discussed the potential of using different SAR data sources such as ERS-1/2 (Lu et al. 2005; Lu \& Kwoun 2008), JERS-1 (Wdowinski et al. 2004; Wdowinski et al. 2008), 
90 RADARSAT-1/2 (Brisco et al. 2017; Gondwe et al. 2010; Kim et al. 2017; Kim et al. 2009; Lu

91 \& Kwoun 2008; Mohammadimanesh et al. 2018a; Siles et al. 2020), ENVISAT (Wdowinski et

92 al. 2006), ALOS PALSAR-1/2 (Cao et al. 2018; Jaramillo et al. 2018; Kim et al. 2017; Kim et al.

93 2014; Kim et al. 2009; Mohammadimanesh et al. 2018a; Palomino-Ángel et al. 2019; Yuan et al.

94 2017) and TerraSAR-X (Hong et al. 2010b; Mohammadimanesh et al. 2017) to detect water level

95 changes in different types of wetlands. However, most SAR satellites that provide data for

96 previous wetland InSAR studies have a relatively short life span and have been out of operation

97 for years or even two decades. In addition, most of these SAR satellites have long repeat

98 observation cycle (11-46 days), limited swath (15-80 km), and limited accessibility (often

99 requires payment).

100 The Sentinel-1 satellite launched in 2014 is the second latest SAR mission operating at C-

101 band. It provides SAR datasets with a short repeat cycle of 6-12 days and a wide coverage area

$102(250 \mathrm{~km})($ Liao \& Wdowinski 2018), while the perpendicular baseline is well controlled (Torres

103 et al. 2012). The cost-free availability of Sentinel-1 data is also an encouraging factor to

104 investigate the potential use of such data for wetland InSAR applications (Mohammadimanesh et

105 al. 2018b). Despite these benefits, there has been little quantitative analysis of using Sentinel-1

106 data to monitor wetland water level changes. Kundu et al. (2017) applied the Sentinel-1 data to

107 estimate water level changes during the floods in the Lember Basin in October 2016. Hong \&

108 Wdowinski (2017) and Liao \& Wdowinski (2018) reported that the interferograms using

109 Sentinel-1 data show distinct fringe patterns related to water level changes over the Everglades.

110 Zhang et al. (2018) used the Sentinel-1 data to extend the precise measurement of a single water

111 gauge to a wide area of $29 \mathrm{~km}^{2}$ in the Palmdale in South Florida. Alexakis et al. (2019)

112 discovered that in Agia Lake and Kournas Lake, low vegetation is the most critical parameter

113 that causing volume scattering, leading to low interferometric coherence, and is therefore the

114 limiting factor in estimating water level changes using Sentinel-1 data. Chen et al. (2019) found

115 that in the marsh wetlands of the Great Lakes, the interferometric coherence derived from the

116 Sentinel-1 data is highly correlated with its temporal baseline (i.e., interferogram's time span).

117 However, in wetlands, the relation between the variation of Sentinel-1 interferometric coherence

118 and backscattering intensity is largely unknown. In addition, given that the use of sentinel-1 data

119 for monitoring wetland water level changes is limited to specific pilot sites, the potential use of 
120 such data in wetlands with different vegetation characteristics and environmental variables has

121 not been extensively studied.

122 This study aims to systematically investigate the potential use of Sentinel-1 C-VV data to

123 detect water level changes in marsh wetlands. We used China's Momoge National Nature

124 Reserve as a case study here because it is widely representative of relatively shallow marshes.

125 Also, this reserve is recognized by the Ramsar Convention on Wetlands of International

126 Importance, where each year over $90 \%$ of the world's Siberian Cranes stage on migration in the

127 large shallow water area. Specifically, the study has the following objectives: (1) to analyze the

128 response of Sentinel-1 interferometric coherence to the perpendicular and temporal baseline, and

129 seasonal fluctuation of water depth; (2) to determine the relation between Sentinel-1

130 interferometric coherence and backscattering intensity; and (3) to assess the influence of the

131 coherence level, the stage of the growing season, and the water depth on the accuracy of

132 monitoring water level changes in marsh wetlands using the Sentinel-1 InSAR technique.

\section{2. Materials and Methods}

\section{2.1. Study Area}

135 The Momoge National Nature Reserve (MNNR; 45 42'25"-46 $18^{\circ} 00^{\prime \prime}$ N, $123^{\circ} 27^{\prime} 00^{\prime \prime}-$

$136124^{\circ} 04^{\prime} 33.7^{\prime \prime}$ E) is located in the West Jilin Province, Northeast China, covering an area of

$1371440 \mathrm{~km}^{2}$ (Figure 1). The reserve has wetland types that are typical to the biogeographic

138 region, such as low plain marshes and shallow lakes. Two large rivers flow through the area,

139 the Nenjiang and Tao'er Rivers, and there are several man-made ditches connecting the water

140 bodies in the reserve. These habitats provide important refuge for a variety of fish, bird, and

141 other wildlife populations. In spring 2012, 97\% of the world's population of the critically

142 endangered Siberian Crane Leucogeranus were recorded at the site, and over 100,000 water

143 birds were recorded in each year between 2010 and 2012 (https://rsis.ramsar.org/ris/2188). In

144 the light of the above, the MNNR was included on the List of Wetlands of International

145 Importance (Ramsar sites) in 2013. The Baihe Lake formerly known as Etou Lake, which is

146 located in the middle of the MNNR, is the main stopover site for Siberian Cranes (Wang et al.

147 2013). The region has a temperate continental monsoon climate with an annual precipitation of

$148389.4 \mathrm{~mm}$, an annual temperature of $4.2^{\circ} \mathrm{C}$, and an annual evaporation (E601) rate up to 1000

$149 \mathrm{~mm}$. Precipitation is concentrated in the summer, making more than $90 \%$ of the annual total 
150 precipitation during the period from May to October. Figure 2 depicts the total precipitation $151(\mathrm{~mm})$ in the study area for each month in 2016.

\section{2.2. Field Data Collection}

153 Six experimental Odyssey ${ }^{\circledR}$ Capacitance water level loggers were installed in the marsh

154 wetlands of the Baihe Lake to automatically monitor the water level in 2016. The six

155 automated water level monitoring sites are located at $\left(45^{\circ} 54^{\prime} 25^{\prime \prime} \mathrm{N}, 123^{\circ} 41^{\prime} 08^{\prime \prime} \mathrm{E}\right)$,

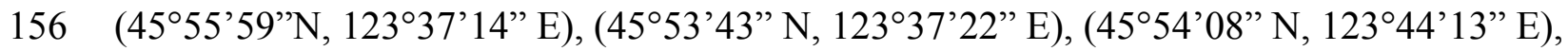
157 (45 $\left.53^{\circ} 28^{\prime \prime} \mathrm{N}, 123^{\circ} 43^{\prime} 19^{\prime \prime} \mathrm{E}\right)$ and $\left(45^{\circ} 52^{\prime} 56^{\prime \prime} \mathrm{N}, 123^{\circ} 44^{\prime} 42^{\prime \prime} \mathrm{E}\right)$, respectively. The water level

158 loggers at sites 1, 2, 4 and 5 were set to take hourly records for the entire study period from 159 May 27, 2016 to October 24, 2016, while the logger at site 3 was set to take records at the same 160 frequency from June 05, 2016 to October 24, 2016. The acquisition time (22:00) of the water 161 level/depth data we used was closest to the transit time ( 22:00) of the Sentinel-1 radar 162 satellite. Records from the six field water level loggers were used to calibrate the water level 163 changes obtained through the Sentinel-1 InSAR technique.

\subsection{Satellite Data Collection}

165

166

167

168

169

\subsubsection{Optical Satellite Image}

The Landsat 8 OLI Land Surface Reflectance Level-2 data product at a 30-meter spatial resolution acquired on October 6, 2016 were gathered from the USGS web portal (https://earthexplorer.usgs.gov/) and were used to generate the land use and land cover (LULC) map for the study area.

\subsubsection{SAR Satellite Image}

A total number of eight VV-polarized Sentinel-1A/B C-band Level-1 images in Interferometric Wide Swath Mode (IW) Single Look Complex (SLC) format acquired on May 27, June 08, July 26, August 07, August 19, September 12, September 30 and October 24 were downloaded from the ESA web portal (https://scihub.copernicus.eu/). These images were used to generate backscatter, coherence, interferograms and water level change maps. The Sentinel-1 synthetic aperture radar $(\mathrm{SAR})$ instrument has a spatial resolution of $5 \mathrm{~m} \times 20 \mathrm{~m}$. All Sentinel-1 SAR images completely covered the study area. 
178

179

180

181

182

183

184

185

186

187

188

189

190

191

192

193

194

195

196

197

198

199

200

201

202

203

204

205

206

207

\subsubsection{DEM}

A digital elevation model (DEM) with a spatial resolution of $12.5 \mathrm{~m}$ derived from ALOS PALSAR-1 imagery acquired on November 12, 2006 was obtained from the Alaska Satellite Facility web portal (https://www.asf.alaska.edu/). The DEM was employed to geocode the SAR images as well as flatten the interferograms.

\subsection{Methodology}

\subsubsection{Steps of the Methodology}

The methods mainly include supervised maximum likelihood classification (MLC), InSAR technique and least square fit analysis. Figure 3 describes the detailed steps of the methodology.

\subsubsection{LULC Classification Based on Maximum Likelihood Classifier}

LULC classification is the stage of image analysis in which the multivariate quantitative measurement associated with each pixel is translated into a label from a pre-defined land use category (Deilmai et al. 2014). The main steps of LULC classification may include determination of a suitable classification system, image pre-processing, selection of training samples, feature extraction, selection of suitable classification approaches, post-classification processing and accuracy assessment (Deilmai et al. 2014).

Before classification, eight land cover types were defined for the study area based on our knowledge of the area, including Marsh, Water, Ditch, Dam, Cropland, Forest, Residential and Saline Soil. The ENVI software (version 5.5.2, Harris Geospatial Solutions, Inc., Broomfield, CO, USA) was used for image processing and analysis. During the pre-processing stage, the seven single-band image files were stacked into one multi-band image file. Then, the image was cropped to the study area size. After that, band combinations 432, 543, 564 and 654 were used flexibly to make composite images. Due to the lack of ground truth samples, training samples were interactively created on the composite images using the "Region of Interest (ROI)" tools provided by ENVI Software with the assistance of the Google Earth historical images acquired in 2016 (Jia et al. 2014). The spatial resolution of the Google Earth historical images ranged from $0.21 \mathrm{~m}$ to $13.30 \mathrm{~m}$. The sizes of the ROIs varied depending on the land cover features. In addition, the ROI separability (i.e., Jeffries-Matusita and Transformed Divergence) was computed and the ROIs were re-selected until the value of Jeffries-Matusita and Transformed Divergence was greater than 1.85 . Table 1 summarizes the characteristics of the final ROIs. 
MLC is especially suitable for the classification of moderate resolution remote sensing images (e.g., Landsat 8 OLI images with a spatial resolution of $30 \mathrm{~m}$ in this study) and has a high

210 overall accuracy (mostly over 80\%) (Deilmai et al. 2014). For this reason, we used MLC rule for

211 the spectral classification of the Landsat 8 OLI images. After classification, the "Edit

212 Classification Image" tools were used for post-classification processing refers to the process of

213 removing the noise and improving the quality of the classified output. After post-classification

214 processing, the accuracy of the classified images was assessed using reference data (i.e., the

215 previously mentioned Google Earth historical images of year 2016). A total of 240 points were

216 selected from the Google Earth historical images generating via a stratified random sampling

217 method. Precision (user's accuracy), recall (producer's accuracy), F1, overall accuracy, and the

218 Kappa statistics were derived from the confusion matrix to find the accuracy and reliability of

219 the maps produced (Islam et al. 2018; Tharwat 2018).

220

221

222

223

224

225

226

227

228

229

230

231

232

233

234

235

236

237

\subsubsection{Backscatter Generation}

The SARscape (version 5.5.2) which is a modular set of ENVI software was applied to generate backscatter for the multitemporal SAR images. The processing consisted of several steps, including reading the Sentinel-1 SLC time series images, generating the 'four range and one azimuth' multilook intensity images to enhance the radiometric resolution of the radar signal and the signal/noise ratio, co-registration, filtering through a Gaussian Gamma MAP filter with a kernel of $5 \times 5$ pixels to decrease the speckle, and using the Range-Doppler approach for geocoding. After that, the obtained intensity values were converted into normalized backscattering coefficient $\left(\sigma^{0}\right)$ values in decibel.

After producing SAR backscatter images, an analysis of $\sigma^{0}$ variation was carried out for the marsh wetlands. We use a multitemporal backscattering response for Sentinel-1 C-VV to identify stable/unstable areas in time. Using all available imagery, we calculated backscatter standard deviation values $\left(S D_{\sigma^{0}}\right)$ in $\mathrm{dB}$. We selected threshold value of $2 \mathrm{~dB}$ (Kim et al. 2013) for sentinel-1 to determine stable/unstable backscatter areas. Pixels with $S D_{\sigma_{0}}$ lower than $2 \mathrm{~dB}$ were considered as stable scatters areas, while with $S D_{\sigma^{0}}$ higher than $2 \mathrm{~dB}$ were considered as unstable scatters areas. The marsh wetlands were further divided into two categories: stable areas of the marsh wetlands and unstable areas of the marsh wetlands accordingly. In the next section, some analyses were carried out in stable areas of the marsh wetlands to minimize seasonal effects 
238

239

240

241

242

243

244

245

246

247

248

249

250

251

252

253

254

255

256

257

258

259

260

261

262

263

264

265

266

267

associated with the changes of seasonal water level and vegetation, some analyses were carried out in unstable areas of the marsh wetlands to investigate the seasonal effects, and the rest analyses were carried out in the whole marsh wetlands. ArcGIS software (version 10.7, ESRI Inc., Redlands, CA, USA) was applied for the above processing.

\subsubsection{InSAR Processing}

The InSAR Processing includes coherence generation, interferogram generation, and water level changes map generation.

Interferometric coherence calculation is a well-known method to examine the quality of the interferograms and represents the degree of similarity of the same pixel in the time span between two SAR acquisitions (i.e., the so-called master and slave SAR images) (Brisco et al. 2015; Guarnieri \& Prati 1997; Mohammadimanesh et al. 2018a). Coherence is calculated by crosscorrelation of the master and slave SAR images over a small window of pixels (Ferretti et al. 2007):

$$
\gamma=\frac{\left\langle s_{1} s_{2}^{*}\right\rangle}{\sqrt{\left\langle s_{1} s_{1}^{*}\right\rangle\left\langle s_{2} s_{2}^{*}\right\rangle}}
$$

where $S_{1}$ and $S_{2}$ denote the complex pixel values of backscattering coefficient, * refers to the complex conjugate, and pixel values within $<$ denote their spatial averaging over a selected window size. $\gamma$ ranges from 0 (low) to 1 (high); $\gamma$ is equal to 1 when the two images are exactly the same, whereas $\gamma$ is equal to 1 when the two images are do not correspond.

In this study, all interferometric processing was carried out using the SARscape module. We started with a baseline estimation to obtain information about both the perpendicular and the temporal baseline values in a multi-temporal SAR acquisitions series. The values for all possible interferometric pair combinations were calculated. After that, we generated "four range and one azimuth" multilook images to enhance the radiometric resolution of the radar signal and the signal/noise ratio, increase the interferometric coherence, and speed up the computing process. A digital elevation model with a spatial resolution of $12.5 \mathrm{~m}$ was employed to flatten the interferograms through the removal of the constant phase due to the acquisition geometry. Interferograms were filtered for visual inspection and for identification of fringe patterns through a Goldstein filter (Goldstein \& Werner 1998) with a $5 \times 5$ size filtering moving window for the coherence estimation. Given that the interferometric phase could not be maintained in herbaceous wetlands when the interferometric coherence was lower than 0.2 (Kim et al. 2013), 
268 we subsequently selected threshold of coherence as 0.2 for unwrapping this phase change with

269 the minimum cost flow unwrapping algorithm and using the Range-Doppler approach for

270 geocoding. It is worth noting that, coherence lower than the unwrapping threshold value $(0.2)$

271 had not transformed from phase into water level change. At last, we converted the unwrapped

272 phase change to water level change $(\Delta h)$ employing the following equation:

$$
\Delta h=-\frac{\lambda \Delta \phi}{4 \pi \cos \theta}+\mathrm{n}
$$

273

274

275

276

277

278

279

280

281

282

283

284

285

286

287

288

289

290

291

292

293

294

In this equation, $\lambda$ and $\theta$ are the Sentinel-1 C-VV SAR wavelength $(0.055 \mathrm{~m})$ and incidence angle $\left(39.1^{\circ}\right)$ respectively, $\Delta \phi$ forms the extracted phase change along the line-of-sight of the satellite in each pixel of the entire study area (in terms of $2 \pi$ ), and $n$ is the noise mainly caused by the above mentioned decorrelation effects. Each color cycle corresponded to approximately $0.035 \mathrm{~m}$ of water level changes in vertical direction, that is $\Delta h$.

\subsubsection{Least Square Fit Analysis}

We used a least square fit analysis to evaluate the relationship between Sentinel-1 interferometric coherence and backscatter variation. The relation was described by the following equation:

$$
y=a+b x
$$

where $\mathrm{a}$ and $\mathrm{b}$ denote the offset and slope, respectively. Only interferometric coherence pairs with the smallest temporal baselines were used and the mean backscatter images were generated by averaging two SAR images, which produced the corresponding coherence images (Mohammadimanesh et al. 2018a).

In order to assess the accuracy of the InSAR-observed water level changes, we used a least square fit between InSAR and logger observations with the line passed through as many points as possible. Because the InSAR and logger observations differ by unknown offset, we addressed the problem by assuming a slope of 1 between two observations (Hong et al. 2010a; Wdowinski et al. 2008). The relation was described by the following equation:

$$
y=x+\text { offset }
$$

Origin software (version 2018C, Origin Lab Corporation, Northampton, MA, USA) was applied for the above processing. 


\section{Results}

296

297

298

299

300

301

302

303

304

305

306

307

308

309

310

311

312

313

314

315

316

317

318

319

320

321

322

323

324

\subsection{Land Use Land Cover Analysis}

Much of the Momoge National Nature Reserve in 2016 was covered by cropland (Figure 4), which contributed $37.0 \%$ of the total area. With $28.9 \%$, marsh wetlands in the reserve were the second largest cover type. The other cover types included $18.9 \%$ for water, $7.6 \%$ for bare saline soil, $4.9 \%$ for forest, and $1.5 \%$ for residential area. Furthermore, in addition to water surface area of the two natural rivers, man-made ditches accounted for $0.64 \%$ of the reserve area; the dam class that obstructed hydrological connectivity accounted for $0.59 \%$. Tables 2 and 3 summarize the results of the confusion matrix and the classification metrics, respectively. As seen, the classification accuracy was high and reliable.

\subsection{Backscatter Analysis}

Figure 5 depicts stable and unstable backscatter areas of the marsh wetlands. The stable and unstable areas of the marsh wetlands cover $249.72 \mathrm{~km}^{2}$ and $172.49 \mathrm{~km}^{2}$, respectively. In fact, fieldwork evidence suggests that the vegetation types of the stable areas were mainly Carex tato and Calamagrostis angustifolia communities that widely distributed along the west bank of Nenjiang River, while the unstable areas were mainly Phragmites australis and Scripus triqueter communities.

\subsection{Coherence Analysis}

Based on analysis of 28 coherence maps, we found that the perpendicular (geometrical) baseline varies within the range between $4.85 \mathrm{~m}$ and $146.26 \mathrm{~m}$ (Figure 6), far less than the critical perpendicular baseline which was about $5188 \mathrm{~m}$. The well controlled perpendicular baseline makes the Sentinel-1 C-VV interferometric coherence independent of the perpendicular baseline (Figure 6). We also found that the temporal baseline ranges from 12 days to 150 days (Figure 6). Besides, the coherence was high (higher than 0.3 in most cases) over the relatively short temporal baseline (i.e., $<24$ days) and low (lower than 0.3 in most cases) over the relatively long temporal baseline (i.e., $>24$ days) (Figure 6). The results indicate that the Sentinel-1 C-VV interferometric coherence is strongly dependent on the temporal baseline. Comparing Figures 7 and 8 shows the response of Sentinel-1 C-VV interferometric coherence to the changes of seasonal water depth. As seen in Figure 7, in general, the mean coherence value decreased dramatically from the interferometric pair of May 27, 2016 and June 
32508,2016 to the interferometric pair of August 19, 2016 and September 12, 2016 and reached its

326 minimum value (0.31), while increased greatly from the interferometric pair of August 19, 2016

327 and September 12, 2016 to the interferometric pair of September 30, 2016 and October 24, 2016

328 and reached its maximum value (0.50). As seen in Figure 8, most of the average water depth on

329 the acquired dates of the interferometric pairs were lower than $1 \mathrm{~m}$, except for all of the

330 interferometric pairs at site 1, the interferometric pair of August 19, 2016 and September 12,

3312016 at sites 5 and 6, as well as the interferometric pair of September 12, 2016 and September

33230,2016 and the interferometric pair of September 30, 2016 and October 24, 2016 at sites 3, 5

333 and 6, which were higher than $1 \mathrm{~m}$. It is worth noting that, in general, the mean water depth

334 presented an opposite variation characteristic compared with the mean coherence value from the

335 interferometric pair of May 27, 2016 and June 08, 2016 to the interferometric pair of August 19,

3362016 and September 12, 2016 (see Figures 7 and 8), indicate that the coherence is strongly

337 influenced by the changes of seasonal water depth. However, the mean coherence value

338 presented an similar variation characteristics compared with the mean water depth between the

339 interferometric pair of August 19, 2016 and September 12, 2016 and the interferometric pair of

340 September 12, 2016 and September 30, 2016, this is because the mean water depth is not the

341 only factor affecting the coherence, vegetation canopy could also influence the coherence and

342 maybe the dominant factor from late August to the end of September in the study area.

343 Figure 9 analysis indicates a negative linear relationship between Sentinel-1 C-VV

344 interferometric coherence and backscattering, suggesting that a high coherence is a good

345 indicator of a low backscattering response for the marsh wetlands. It is worth noting that,

346 although the temporal baseline was within 24 days, the mean coherence was lower than 0.55.

347 Besides, the mean backscatter coefficient shows a relatively narrow range of variation between -

$348 \quad 11.74$ and -10.58 .

\section{3.4. Interferogram Analysis}

350 Interferograms of phase changes are listed in Figure 10. Comparing Figures 7 and 10, it can

351 be found that although the mean coherence of the interferometric pairs was high, most of the

352 interferograms did not exhibit distinct fringes except for the interferometric pair of July 26, 2016

353 and August 07, 2016 (see Figure 10b). In addition, the phase changes did not complete a full

354 phase change (i.e., $<2 \pi$ ) in most areas for the interferometric pair of July 26, 2016 and August 
35507,2016 , indicate that the water level change was less than $0.035 \mathrm{~m}$ in vertical direction in most 356 areas.

\section{3.5. Water Level Change Analysis}

358 The calibration was conducted between the InSAR data and the logger data (Figure 11).

359 The calibration plots show poor agreement between InSAR and logger data for all

360 interferometric pairs, no matter in relatively shallow flooding marsh wetlands (water depth

361 lower than $1 \mathrm{~m}$ ) (Figure 11a), or in relatively deep flooding marsh wetlands (water depth

362 higher than $1 \mathrm{~m}$ ) (Figure 11b). When the calibration plot shows a good agreement between

363 InSAR and in-situ data for the interferometric pair of July 26, 2016 and August 07, 2016, only

364 four observations are available (Figure 11c).

\section{4. Discussion}

366 As expected, no dependency of the interferometric coherence was found with the

367 perpendicular baseline for Sentinel-1 C-VV data. However, interferometric coherence appeared

368 to be strongly dependent on the temporal baseline (Figure 6), which agrees with that reported by

369 Chen et al. (2019). It is also worth noting that a temporal baseline of no more than 24 days is

370 required to maintain a coherence of greater than 0.3 for Sentinel-1 C-VV data, while the

371 coherence would be lower than 0.3 if the temporal baseline exceeds 24 days in most cases

372 (Figure 6). Currently, the Sentinel-1 A and B constellation can deliver a six-day repeat cycle in

373 Europe. Besides, a new generation of SAR satellites, the C-band RADARSAT Constellation

374 Mission (RSM) with a resolution of $1 \mathrm{~m} \times 3 \mathrm{~m}$ and a repeat cycle of 4 days, was launched by the

375 Canadian Space Agency in June 2019. Thus, more work is needed to investigate whether a better

376 coherence could be obtained in the even shorter temporal baselines (i.e., six days and four days

377 interval) for C-band SAR data.

378 The negative correlation between Sentinel-1 coherence and water depth during the early

379 stage of growing season (Figures 7 and 8) indicates the importance of considering seasonality in

380 wetland InSAR analysis. This is because the deeper a water body is and the larger the water

381 surface area is, the lower the double bounce scattering will be during the early growth stage of

382 emerging vegetation when plants have a less developed canopy. However, during the late stage

383 of the growing season (from middle September to late October), the Sentinel-1 coherence has no

384 close relationship with water depth (Figures 7 and 8). This may probably be due to the developed 
385 vegetation canopy, which led to high double bounce scattering, making it the main factor

386 determining interferometric coherence. This finding is different than that reported by Alexakis et

387 al. (2019) who found that coherence values decreased with increasing NDVI in Agia Lake in

388 Greece during a summer period.

389 A nearly linear negative correlation was found between Sentinel-1 C-VV interferometric

390 coherence and backscatter for the marsh wetlands in China's Momoge National Nature Reserve

391 (Figure 9), indicating that a high coherence is a good indicator of a low Sentinel-1 backscattering

392 response for the marsh wetlands. Our finding differs from previous studies (Kim et al. 2013;

393 Mohammadimanesh et al. 2018a) which found that there is no linear correlation between

394 interferometric coherence and backscattering for the marsh wetlands when using JERS-1,

395 RADARSAT-1/2, ERS-1/2, ALOS PALSAR-1 and TerraSAR-X data. In addition, the range of

396 the Sentinel-1 C-VV backscatter was relatively narrow for the stable areas of the marsh wetlands

397 (i.e., mainly Carex tato and Calamagrostis angustifolia communities) in the MNNR (Figure 9)

398 as compared to that of reed marshes in Balikdami wetland in Turkey (Kaplan \& Avdan 2018).

399 More work is needed in the future to distinguish whether the main backscattering mechanism in

400 the MNNR is double bounce scattering or volume scattering.

$401 \quad$ For the first time, we have found that once the coherence exceeds a certain threshold $(0.3$ in 402 this study), the stage during the growing season, rather than the coherence, is the primary factor 403 determining the quality of the interferogram for the marsh wetlands, even though the quality of 404 the interferogram largely depends on the coherence. Comparing Figure 10 and Figure 12, it can 405 be found that the interferometric pair of July 26, 2016 and August 07, 2016 exhibits the best 406 quality of the interferogram but the third highest coherence. However, most of the interferograms 407 in the study area did not exhibit distinct fringes, which is contrary to that reported by Hong \& 408 Wdowinski (2017) and Liao \& Wdowinski (2018) for the Florida Everglades.

409 If the Sentinel-1 data has a potential to be used for monitoring wetland water levels in the 410 study area, it will be able to guide the conservation and restoration of the habitat of endangered 411 Siberian Cranes. However, unfortunately, the Sentinel-1 C-VV data did not perform well in 412 monitoring the water level changes in the marsh wetlands in the study area, although its 413 coherence was high enough (Figures 11 and 12). A possible explanation for this is that the 414 specific vegetation characteristics and environmental variables in the study area may have caused 415 insufficient double bounce backscattering. In addition, due to the limited calibration data, we are 
416 not sure whether Sentinel-1 data has a good performance in the interferometric pair of July 26, 4172016 and August 07, 2016. Our finding is contrary to those from several previous studies 418 (Alexakis et al. 2019; Hong \& Wdowinski 2017; Kundu et al. 2017; Liao \& Wdowinski 2018; 419 Zhang et al. 2018) which have shown that the Sentinel-1 C-band data can be used to monitor 420 wetland water level changes in other regions. Nevertheless, the analysis of the potential use of 421 Sentinel-1 C-VV data for detecting wetland water level changes undertaken here, has extended 422 our knowledge of the applicability of such data. Further studies are needed in the future to 423 discern whether a better accuracy could be obtained in other stopover sites for Siberian Cranes 424 with different vegetation characteristics and environmental variables when using Sentinel-1 425 InSAR technique for detecting water level changes.

\section{Conclusions}

This study utilized 28 repeat-pass Sentinel-1 imagery to comprehensively investigate SAR backscatter and coherence variation for marsh wetlands in China's Momoge National Nature Reserve, a Ramsar recognized wetland site of international importance. The higher temporal resolution of the Sentinel-1 images allowed us assessing the potential of using InSAR applications for wetland dynamic analysis. Our study showed that coherence was mainly dependent on the temporal baseline, not affected by the perpendicular baseline for Sentinel-1 CVV data collected over the marsh wetlands. A negative correlation between Sentinel-1 coherence and water depth was found for the marsh wetlands during the early growth stage of vegetation, indicating the role of water depth in determining the coherence during the early growth stage of vegetation. For the late growth stage, marsh vegetation canopy can play a key role in determining the coherence. A nearly linear negative relation between Sentinel-1 C-VV coherence and backscatter were found for the marsh wetlands, suggesting that a high coherence is a good indicator of a low Sentinel-1 backscattering response for the marsh wetlands. We found that although the quality of the interferogram largely depends on the coherence, the stage during the growing season, rather than the coherence, is the primary factor in determining the quality of the interferogram for the marsh wetlands. Our findings demonstrate that Sentinel-1 C-VV data is generally not suitable to be used for monitoring water level changes through InSAR technique in marsh wetlands of the China's Momoge National Nature Reserve because of its poor accuracy. 


\section{References}

446 Alexakis D, Stavroulaki E, and Tsanis I. 2019. Using Sentinel-1A DInSAR interferometry and Landsat 8 data for monitoring water level changes in two lakes in Crete, Greece. Geocarto International 34:703-721.

Alsdorf DE, Melack JM, Dunne T, Mertes LA, Hess LL, and Smith LC. 2000. Interferometric radar measurements of water level changes on the Amazon flood plain. Nature 404:174.

450

451

Alsdorf DE, Smith LC, and Melack JM. 2001. Amazon floodplain water level changes measured with interferometric SIR-C radar. IEEE Transactions on Geoscience and Remote Sensing 39:423-431.

452

Assessment ME. 2005. Ecosystems and human well-being: wetlands and water: World Resources Institute.

453

Bailly J, Arnaud M, and Puech C. 2007. Boosting: a classification method for remote sensing. International Journal of Remote Sensing 28:1687-1710.

Brisco B, Ahern F, Murnaghan K, White L, Canisus F, and Lancaster P. 2017. Seasonal change in wetland coherence as an aid to wetland monitoring. Remote Sensing 9:158.

Brisco B, Murnaghan K, Wdowinski S, and Hong S-H. 2015. Evaluation of RADARSAT-2 Acquisition Modes for Wetland Monitoring Applications. Canadian Journal of Remote Sensing 41:431-439. 10.1080/07038992.2015.1104636

Cao N, Lee H, Jung H, and Yu H. 2018. Estimation of water level changes of large-scale Amazon wetlands using ALOS2 ScanSAR differential interferometry. Remote Sensing 10:966.

Chen Z, White L, Banks S, Behnamian A, Montpetit B, Pasher J, and Duffe J. 2019. InSAR monitoring of marsh wetlands flow dynamics in Great Lakes. IGARSS 2019-2019 IEEE International Geoscience and Remote Sensing Symposium: IEEE. p 6848-6851.

Cole CA, Brooks RP, and Wardrop DH. 1997. Wetland hydrology as a function of hydrogeomorphic (HGM) subclass. Wetlands 17:456-467.

Congalton RG. 1991. A review of assessing the accuracy of classifications of remotely sensed data. Remote Sensing of Environment 37:35-46.

Costanza R, d'Arge R, De Groot R, Farber S, Grasso M, Hannon B, Limburg K, Naeem S, O'neill RV, and Paruelo J. 1997. The value of the world's ecosystem services and natural capital. Nature 387:253.

Currit N. 2005. Development of a remotely sensed, historical land-cover change database for rural Chihuahua, Mexico. International Journal of Applied Earth Observation and Geoinformation 7:232-247.

Deilmai BR, Ahmad BB, and Zabihi H. 2014. Comparison of two Classification methods (MLC and SVM) to extract land use and land cover in Johor Malaysia. 20:012052.

Ferretti A, Monti-Guarnieri A, Prati C, Rocca F, and Massonet D. 2007. InSAR Principles-Guidelines for SAR Interferometry Processing and Interpretation, TM-19. The Netherlands: ESA Publications.

Foody GM. 2002. Status of land cover classification accuracy assessment. Remote Sensing of Environment 80:185-201. 25:4035-4038.

Gondwe BRN, Hong S-H, Wdowinski S, and Bauer-Gottwein P. 2010. Hydrologic Dynamics of the Ground-Water-Dependent Sian Ka'an Wetlands, Mexico, Derived from InSAR and SAR Data. Wetlands 30:1-13. 
483 Hanssen RF. 2001. Radar interferometry: data interpretation and error analysis: Springer Science \& Business Media.

484 Hong S-H, and Wdowinski S. 2017. A review on monitoring the everglades wetlands in the southern florida using space-based

485

486

487

488

489

490

491

492

493

494

495

496

497

498

499

500

501

502

503

504

505

506

507

508

509

510

511

512

513

514

515

516

517

518

519

520 synthetic aperture radar (sar) observations. 대한원격탐사학회지 33:377-390.

Hong S-H, Wdowinski S, Kim S-W, and Won J-S. 2010a. Multi-temporal monitoring of wetland water levels in the Florida Everglades using interferometric synthetic aperture radar (InSAR). Remote Sensing of Environment 114:2436-2447.

Hong S, Wdowinski S, and Kim S. 2010b. Evaluation of TerraSAR-X Observations for Wetland InSAR Application. IEEE Transactions on Geoscience and Remote Sensing 48:864-873. 10.1109/TGRS.2009.2026895

Hunt RJ, Walker JF, and Krabbenhoft DP. 1999. Characterizing hydrology and the importance of ground-water discharge in natural and constructed wetlands. Wetlands 19:458-472.

Islam K, Jashimuddin M, Nath B, and Nath TK. 2018. Land use classification and change detection by using multi-temporal remotely sensed imagery: The case of Chunati wildlife sanctuary, Bangladesh. The Egyptian Journal of Remote Sensing and Space Science 21:37-47.

Jaramillo F, Brown I, Castellazzi P, Espinosa L, Guittard A, Hong SH, Rivera-Monroy VH, and Wdowinski S. 2018. Assessment of hydrologic connectivity in an ungauged wetland with InSAR observations. Environmental Research Letters 13:10. $10.1088 / 1748-9326 / \mathrm{aa} 9 \mathrm{~d} 23$

Jensen JR. 2005. Thematic information extraction: pattern recognition. Introductory Digital Image Processing: A Remote Sensing Perspective:337-406.

Jensen JR, and Lulla K. 1987. Introductory digital image processing: a remote sensing perspective.

Jia K, Wei X, Gu X, Yao Y, Xie X, and Li B. 2014. Land cover classification using Landsat 8 operational land imager data in Beijing, China. Geocarto International 29:941-951.

Kaplan G, and Avdan U. 2018. Monthly Analysis of Wetlands Dynamics Using Remote Sensing Data. ISPRS International Journal of Geo-Information 7:411.

Kim J-W, Lu Z, Gutenberg L, and Zhu Z. 2017. Characterizing hydrologic changes of the Great Dismal Swamp using SAR/InSAR. Remote Sensing of Environment 198:187-202.

Kim J-W, Lu Z, Jones JW, Shum CK, Lee H, and Jia Y. 2014. Monitoring Everglades freshwater marsh water level using L-band synthetic aperture radar backscatter. Remote Sensing of Environment 150:66-81. https://doi.org/10.1016/j.rse.2014.03.031

Kim J-W, Lu Z, Lee H, Shum CK, Swarzenski CM, Doyle TW, and Baek S-H. 2009. Integrated analysis of PALSAR/Radarsat-1 InSAR and ENVISAT altimeter data for mapping of absolute water level changes in Louisiana wetlands. Remote Sensing of Environment 113:2356-2365. https://doi.org/10.1016/j.rse.2009.06.014

Kim S, Wdowinski S, Amelung F, Dixon TH, and Won J. 2013. Interferometric Coherence Analysis of the Everglades Wetlands, South Florida. IEEE Transactions on Geoscience and Remote Sensing 51:5210-5224. 10.1109/TGRS.2012.2231418

Kundu S, Jung H, Lakshmi V, and Torres R. 2017. Flood extent mapping and water level change using Sentinel-1 data. AGU Fall Meeting Abstracts.

Kwoun O-i, and Lu Z. 2009. Multi-temporal RADARSAT-1 and ERS backscattering signatures of coastal wetlands in southeastern Louisiana. Photogrammetric Engineering \& Remote Sensing 75:607-617.

Liao H, and Wdowinski S. 2018. Exploration of Sentinel-1 InSAR observations for Monitoring Water Level Changes in Everglades Florida. AGU Fall Meeting Abstracts.

Peer) reviewing PDF | (2019:11:43209:1:1:NEW 24 Dec 2019) 
521 Liu C, Frazier P, and Kumar L. 2007. Comparative assessment of the measures of thematic classification accuracy. Remote

$522 \quad$ Sensing of Environment 107:606-616.

523 Liu X-H, Skidmore A, and Van Oosten H. 2002. Integration of classification methods for improvement of land-cover map

$524 \quad$ accuracy. ISPRS journal of photogrammetry and remote sensing 56:257-268.

525 Lu Z. 2007. InSAR imaging of volcanic deformation over cloud-prone areas-Aleutian Islands. Photogrammetric Engineering \&

$526 \quad$ Remote Sensing 73:245-257.

527 Lu Z, Crane M, Kwoun OI, Wells C, Swarzenski C, and Rykhus R. 2005. C-band radar observes water level change in swamp

528 forests. EOS, Transactions American Geophysical Union 86:141-144.

529 Lu Z, and Kwoun O-i. 2008. Radarsat-1 and ERS InSAR analysis over southeastern coastal Louisiana: Implications for mapping $530 \quad$ water-level changes beneath swamp forests. IEEE Transactions on Geoscience and Remote Sensing 46:2167-2184.

531 Manandhar R, Odeh I, and Ancev T. 2009. Improving the accuracy of land use and land cover classification of Landsat data

532 using post-classification enhancement. Remote Sensing 1:330-344.

533 Mitsch WJ, and Gosselink JG. 2015. Wetlands. Hoboken (New Jersey): John Wiley \&Sons, 5th Edition.

534 Mohammadimanesh F, Salehi B, Mahdianpari M, Brisco B, and Motagh M. 2018a. Multi-temporal, multi-frequency, and multi-

535 polarization coherence and SAR backscatter analysis of wetlands. ISPRS journal of photogrammetry and remote

536 sensing 142:78-93.

537

Mohammadimanesh F, Salehi B, Mahdianpari M, Brisco B, and Motagh M. 2018b. Wetland Water Level Monitoring Using

538 Interferometric Synthetic Aperture Radar (InSAR): A Review. Canadian Journal of Remote Sensing 44:247-262.

539 10.1080/07038992.2018.1477680

540

541

542

543

Scholes R, Montanarella L, Brainich A, and Barger N. 2018. Summary for policymakers of the thematic assessment report on

Mohammadimanesh F, Salehi B, Mahdianpari M, and Motagh M. 2017. X-band interferometric sar observations for wetland water level monitoring in newfoundland and labrador. 2017 IEEE International Geoscience and Remote Sensing Symposium (IGARSS): IEEE. p 3159-3162.

Palomino-Ángel S, Anaya-Acevedo JA, Simard M, Liao T-H, and Jaramillo F. 2019. Analysis of floodplain dynamics in the Atrato River Colombia using SAR interferometry. Water 11:875.

Pitcher LH, Pavelsky TM, Smith LC, Moller DK, Altenau EH, Allen GH, Lion C, Butman D, Cooley SW, and Fayne JV. 2019. AirSWOT InSAR mapping of surface water elevations and hydraulic gradients across the Yukon Flats Basin, Alaska. Water Resources Research 55:937-953.

Plourde L, and Congalton RG. 2003. Sampling method and sample placement. Photogrammetric Engineering \& Remote Sensing 69:289-297.

Ramsey III E, Zhong L, Amina R, and Russell R. 2006. Multiple Baseline Radar Interferometry Applied to Coastal Land Cover Classification and Change Analyses. Mapping Sciences \& Remote Sensing 43:283-309.

Richards J, Woodgate P, and Skidmore A. 1987. An explanation of enhanced radar backscattering from flooded forests. International Journal of Remote Sensing 8:1093-1100. land degradation and restoration of the Intergovernmental Science-Policy Platform on Biodiversity and Ecosystem Services. Bonn, Germany: IPBES secretariat. p 10.

Regions. Remote Sensing 8:16. 
559

560

561

562

563

564

565

566

567

568

569

570

571

572

573

574

575

576

577

578

579

580

581

582

583

584

585

586

587

588

589

590

591

592

593

594

595

Siles G, Trudel M, Peters DL, and Leconte R. 2020. Hydrological monitoring of high-latitude shallow water bodies from highresolution space-borne D-InSAR. Remote Sensing of Environment 236:111444.

Smits P, Dellepiane S, and Schowengerdt R. 1999. Quality assessment of image classification algorithms for land-cover mapping: A review and a proposal for a cost-based approach. International Journal of Remote Sensing 20:1461-1486.

Story M, and Congalton RG. 1986. Accuracy assessment: a user's perspective. Photogrammetric Engineering and Remote Sensing 52:397-399.

Tharwat A. 2018. Classification assessment methods. Applied Computing and Informatics.

Tong X, Sandwell DT, and Fialko Y. 2010. Coseismic slip model of the 2008 Wenchuan earthquake derived from joint inversion of interferometric synthetic aperture radar, GPS, and field data. Journal of Geophysical Research: Solid Earth 115.

Torres R, Snoeij P, Geudtner D, Bibby D, Davidson M, Attema E, Potin P, Rommen B, Floury N, and Brown M. 2012. GMES Sentinel-1 mission. Remote Sensing of Environment 120:9-24.

Wang Y, Feng J, Lin Q, Lyu X, Wang X, and Wang G. 2013. Effects of crude oil contamination on soil physical and chemical properties in Momoge wetland of China. Chinese Geographical Science 23:708-715. 10.1007/s11769-013-0641-6

Wdowinski S, Amelung F, Miralles-Wilhelm F, Dixon TH, and Carande R. 2004. Space-based measurements of sheet-flow characteristics in the Everglades wetland, Florida. Geophysical Research Letters 31.

Wdowinski S, and Hong SH. 2015. Wetland InSAR: A review of the technique and applications. Remote Sensing of Wetlands: Applications and Advances: CRC Press, 137-154.

Wdowinski S, Kim S-W, Amelung F, Dixon TH, Miralles-Wilhelm F, and Sonenshein R. 2008. Space-based detection of wetlands' surface water level changes from L-band SAR interferometry. Remote Sensing of Environment 112:681-696.

Wdowinski S, Kim S, Amelung F, and Dixon T. 2006. Wetland InSAR: A new space-based hydrological monitoring tool of wetlands surface water level changes. GlobWetland Symposium Proceedings: Frescati, Itali. p 6.

Weng Q. 2002. Land use change analysis in the Zhujiang Delta of China using satellite remote sensing, GIS and stochastic modelling. Journal of Environmental Management 64:273-284.

Xie C, Shao Y, Xu J, Wan Z, and Fang L. 2013. Analysis of ALOS PALSAR InSAR data for mapping water level changes in Yellow River Delta wetlands. International Journal of Remote Sensing 34:2047-2056.

Xie C, Xu J, Shao Y, Cui B, Goel K, Zhang Y, and Yuan M. 2015. Long term detection of water depth changes of coastal wetlands in the Yellow River Delta based on distributed scatterer interferometry. Remote Sensing of Environment 164:238-253.

Ye X, Kaufmann H, and Guo X. 2004. Landslide monitoring in the Three Gorges area using D-InSAR and corner reflectors. Photogrammetric Engineering \& Remote Sensing 70:1167-1172.

Yuan M, Xie C, Shao Y, Xu J, Cui B, and Liu L. 2016. Retrieval of water depth of coastal wetlands in the Yellow River Delta from ALOS PALSAR backscattering coefficients and interferometry. IEEE Geoscience and Remote Sensing Letters 13:1517-1521.

Yuan T, Lee H, and Jung HC. 2017. Congo floodplain hydraulics using PALSAR InSAR and Envisat altimetry data. Remote Sensing of Hydrological Extremes: Springer, 65-81.

Zebker HA, and Villasenor J. 1992. Decorrelation in interferometric radar echoes. IEEE Transactions on Geoscience and Remote Sensing 30:950-959.

Peer) reviewing PDF | (2019:11:43209:1:1:NEW 24 Dec 2019) 
596 Zhang B, Wdowinski S, Oliver-Cabrera T, Koirala R, Jo M, and Osmanoglu B. 2018. Mapping the extent and magnitude of sever

597

598

599

600

601 flooding induced by Hurricane IRMA with multi-temporal SENTINEL-1 SAR and Insar observations. Int Arch Photogramm Remote Sens Spat Inf Sci 42.

Zhang M, Li Z, Tian B, Zhou J, and Tang P. 2016. The backscattering characteristics of wetland vegetation and water-level changes detection using multi-mode SAR: A case study. International Journal of Applied Earth Observation and Geoinformation 45:1-13. 
Figure 1

Location map of the study area showing the extent and DEM of the Momoge National Nature Reserve (MNNR) in northeast China. Six experimental Odyssey ${ }^{\circledR}$ Capacitance water level loggers were installed in the marsh wetlands of the Baihe Lake in the study area.

Data source: https://www.asf.alaska.edu/

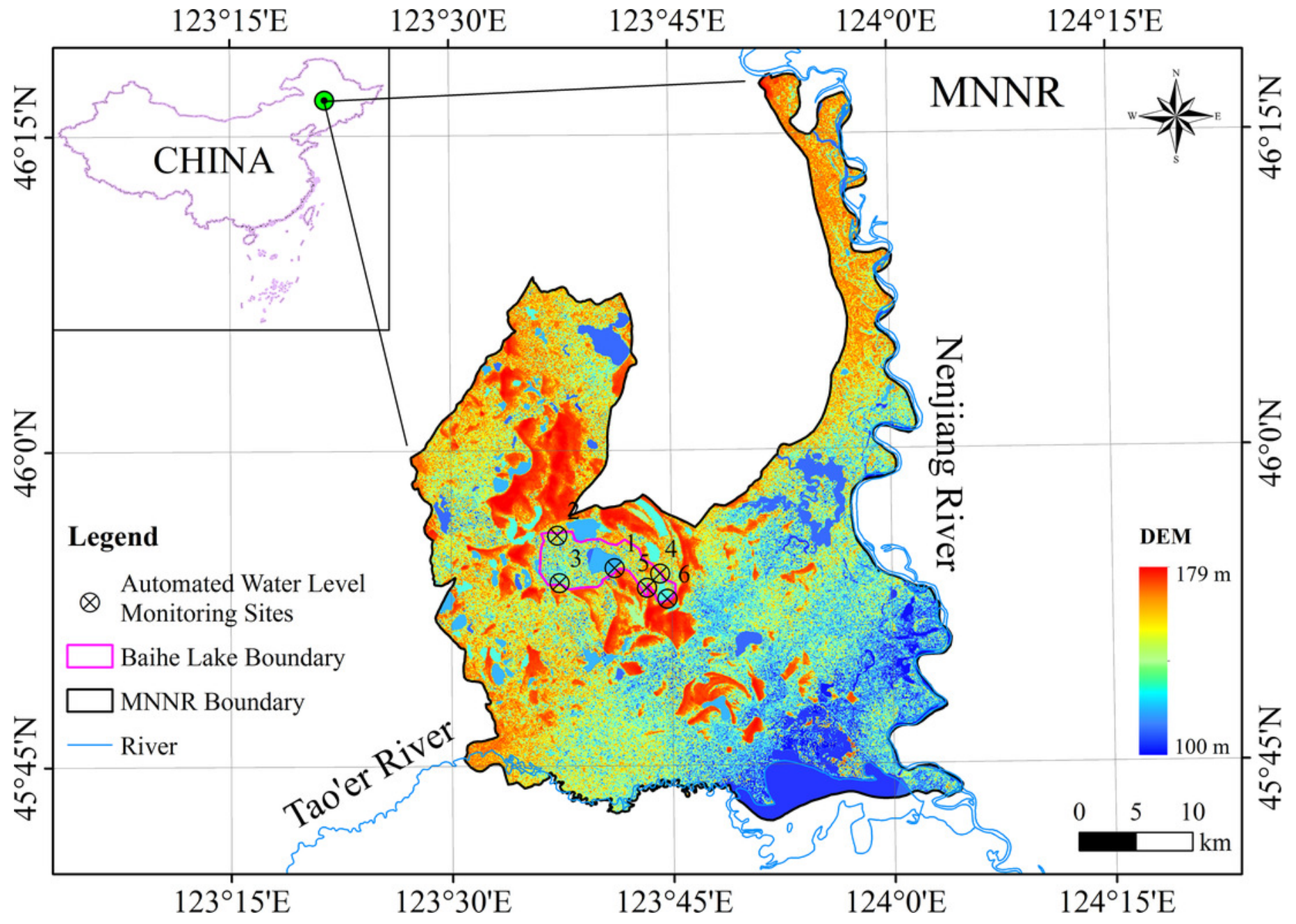


Figure 2

Monthly precipitation in the study area in 2016.

Data were collected from the China Meteorological Data Service Center (http://data.cma.cn).

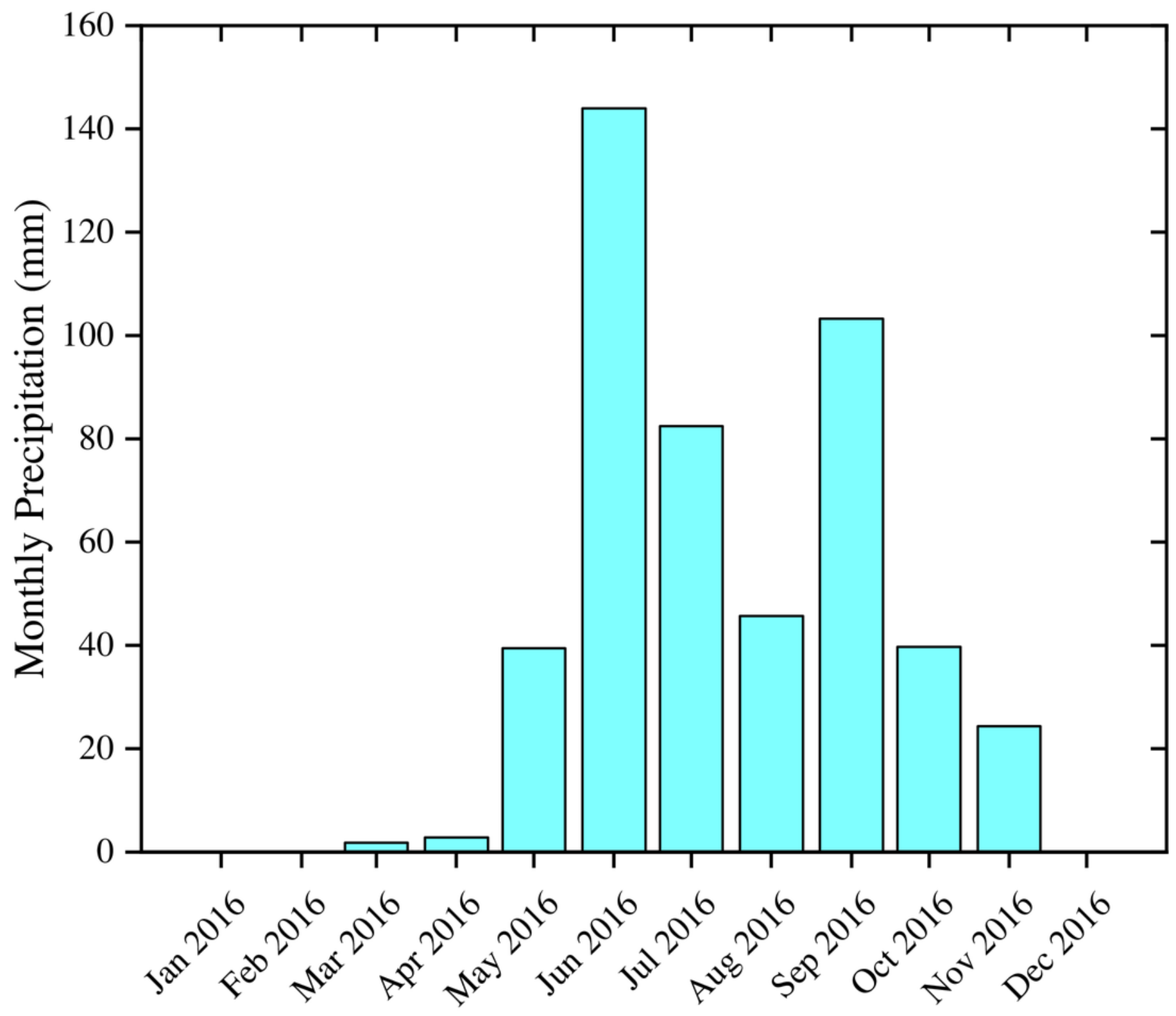


Figure 3

\section{Flowchart of the image processing and data analysis in this study.}

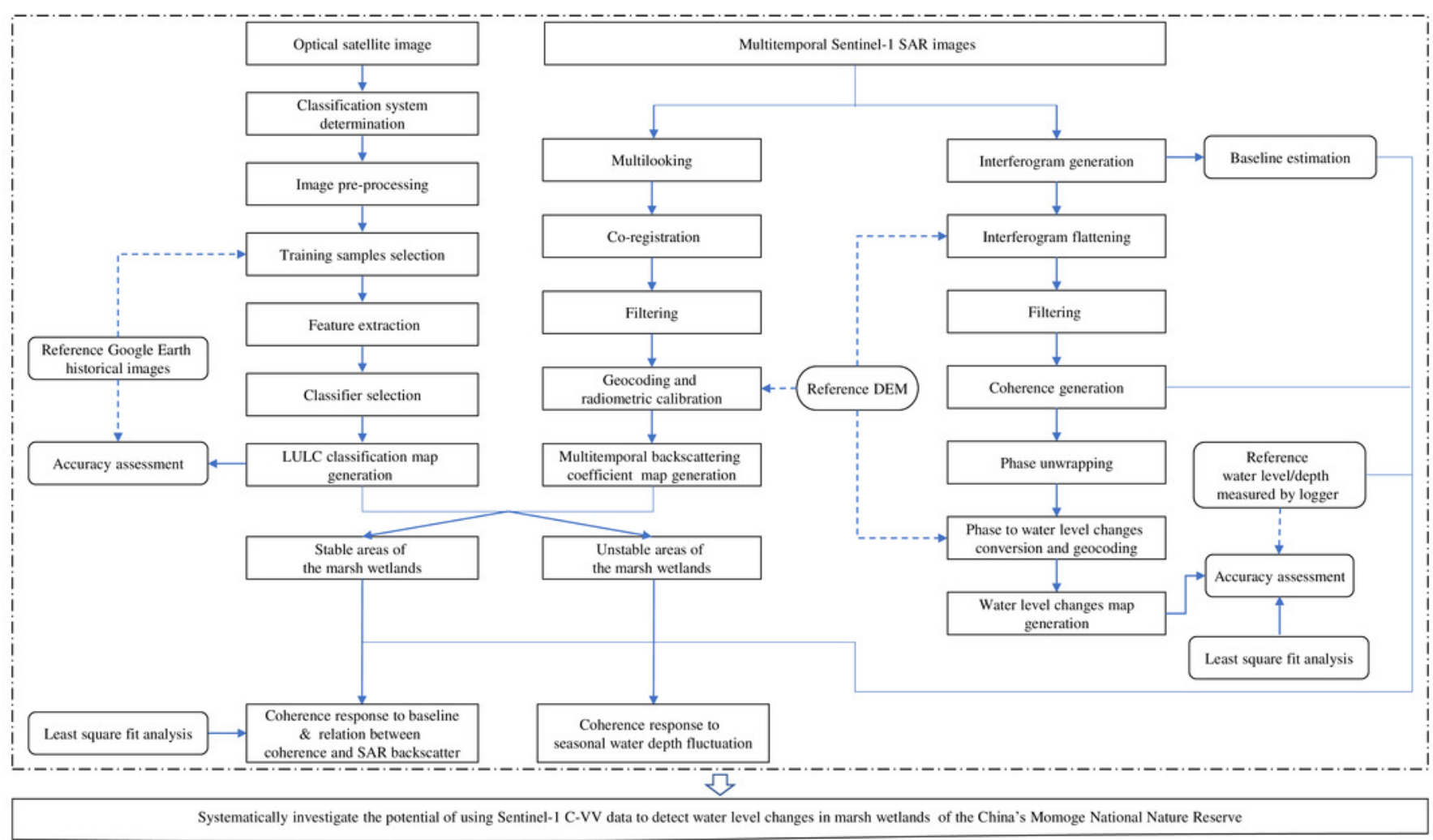


Figure 4

Land use and land cover (LULC) distribution in the Momoge National Nature Reserve, Northeast China.

The map was created with the supervised classification based on satellite image acquired in 2016. Data source: https://earthexplorer.usgs.gov/ 


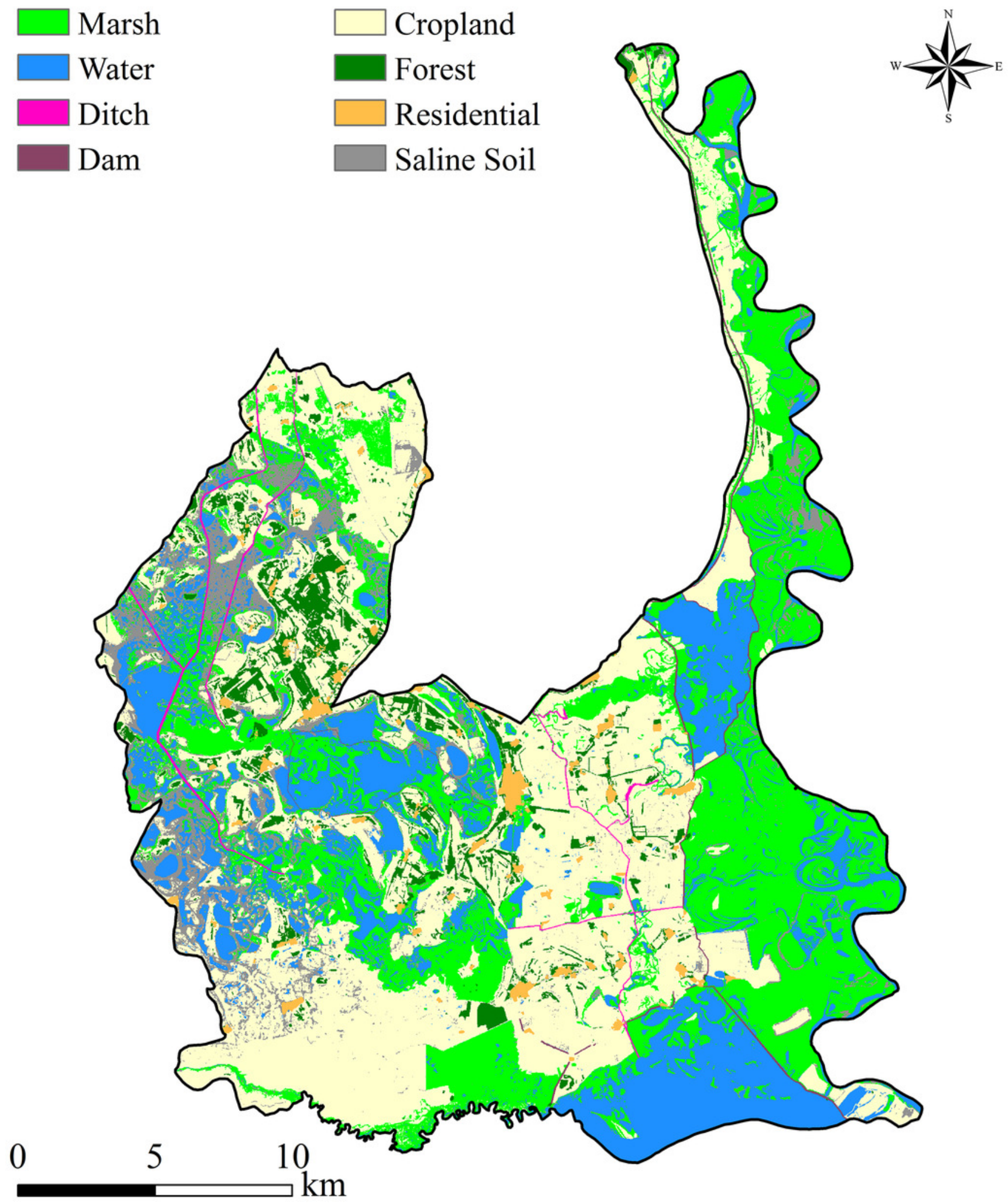




\section{Figure 5}

Marsh wetlands distributionin the Momoge National Nature Reserve, Northeast China, classified with Sentinel-1multitemporal SAR images from May 2016 to October 2016.

Pixels with backscattering standard deviation value lower than $2 \mathrm{~dB}$ were considered as stable scatters, while with backscattering standard deviation value higher than $2 \mathrm{~dB}$ were considered as unstable scatters. Data source: https://scihub.copernicus.eu/ 


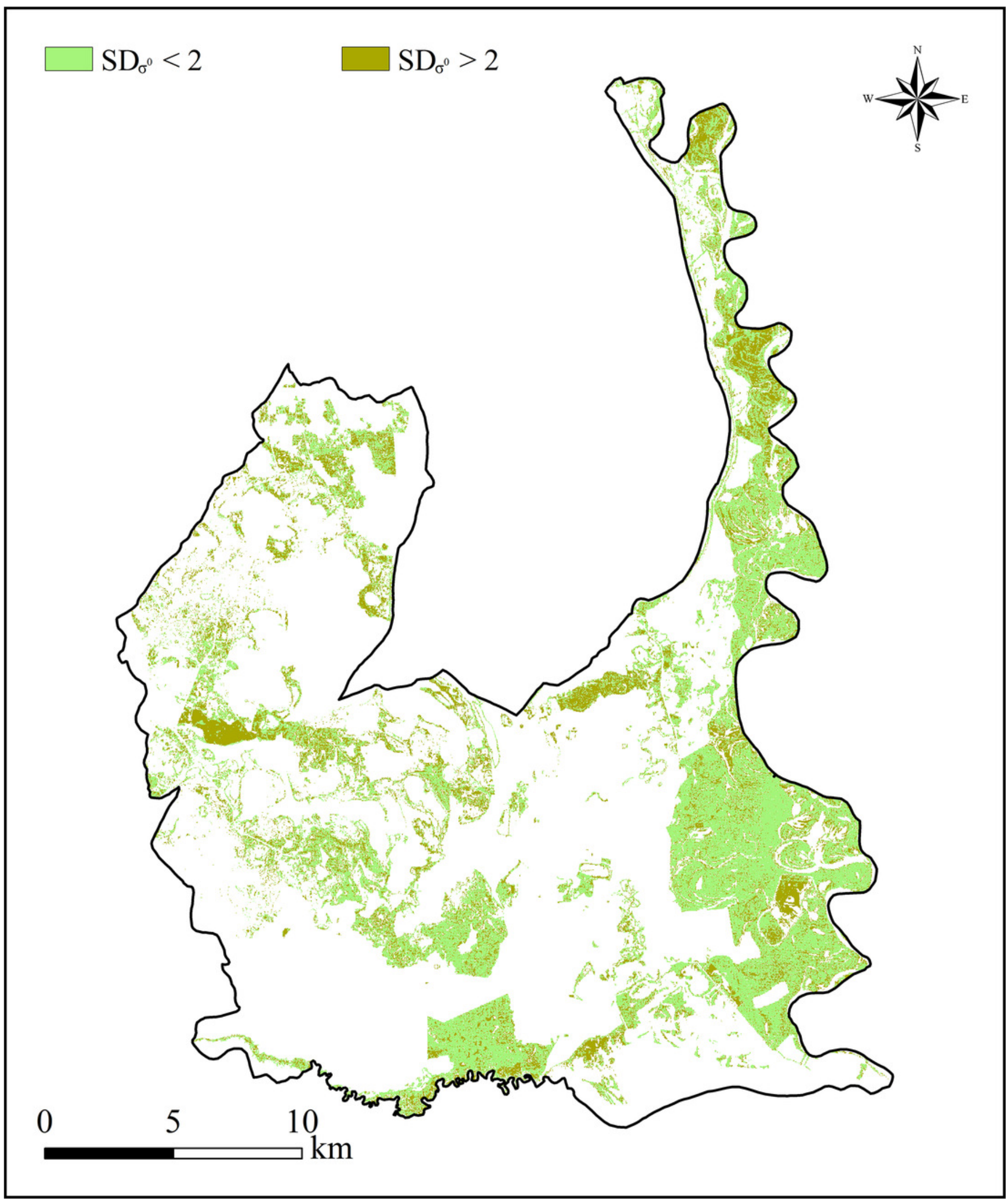


Figure 6

Temporal vs. perpendicular baselines in the Sentinel-1 coherence analysis for stable areas of the marsh wetlands in the Momoge National Nature Reserve, Northeast China.

Dot sizes and colors are proportional to different coherence values.

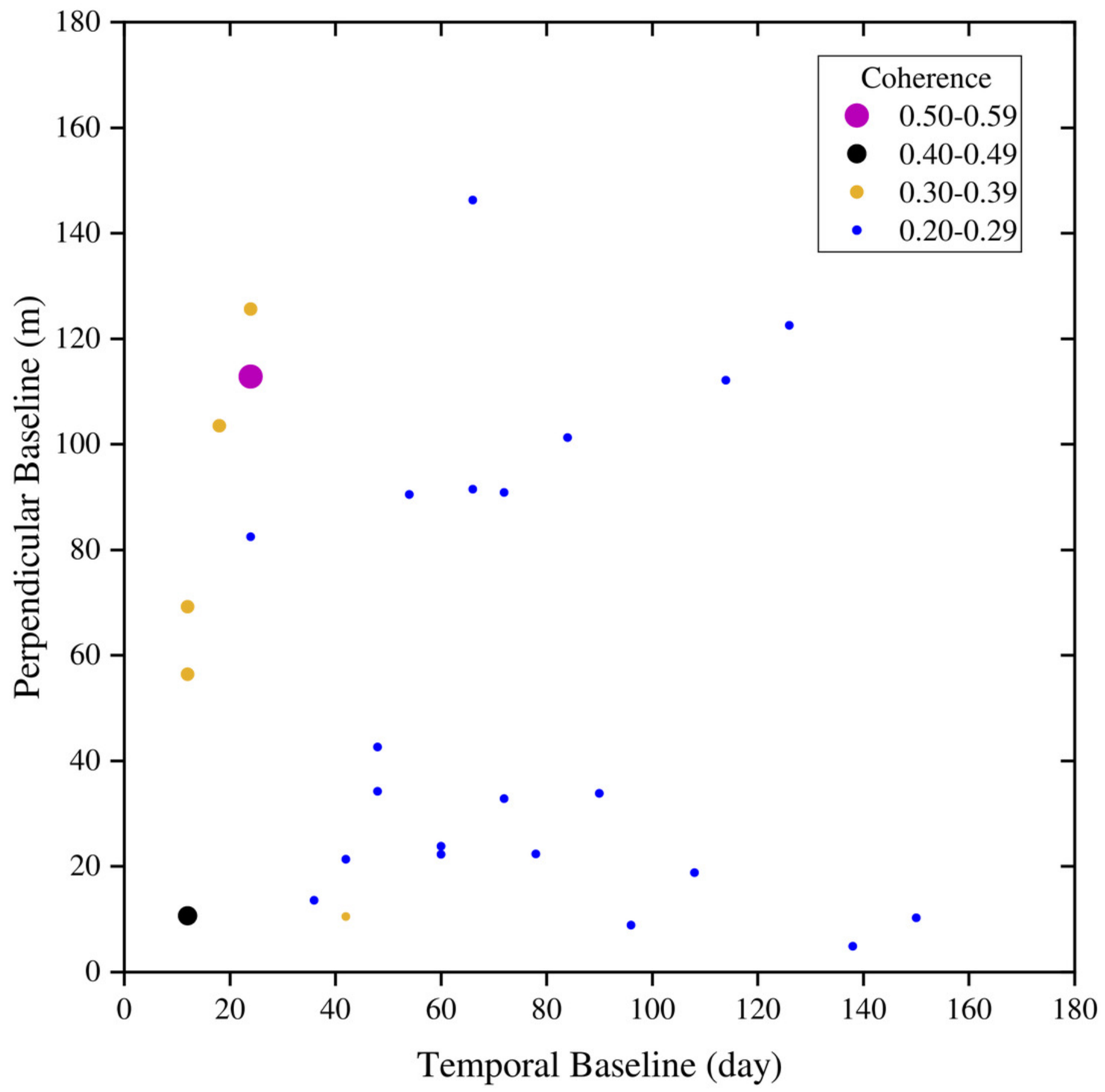


Figure 7

Sentinel-1 coherence analysis results for unstable areas of the marsh wetlands .

The $\mathrm{x}$-axis shows the six interferometric pairs with a short temporal baseline as no more than 24 days.

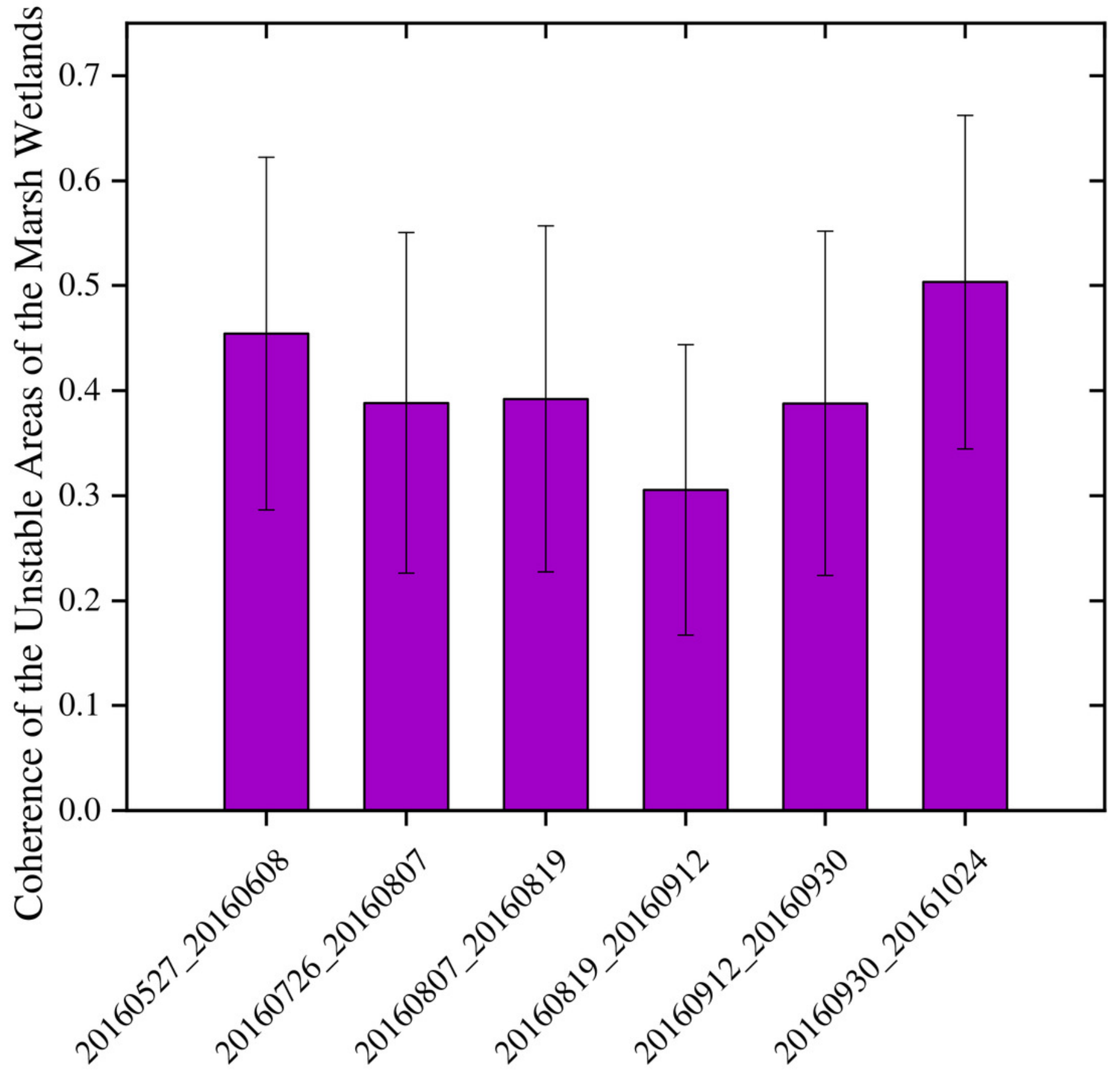


Figure 8

Mean water depths recorded by field water loggers at six monitoring sites in the marsh wetlands of the Baihe Lake, Northeast China.

The $x$-axis shows the acquisition dates of the six interferometric pairs with a short temporal baseline as no more than 24 days. 


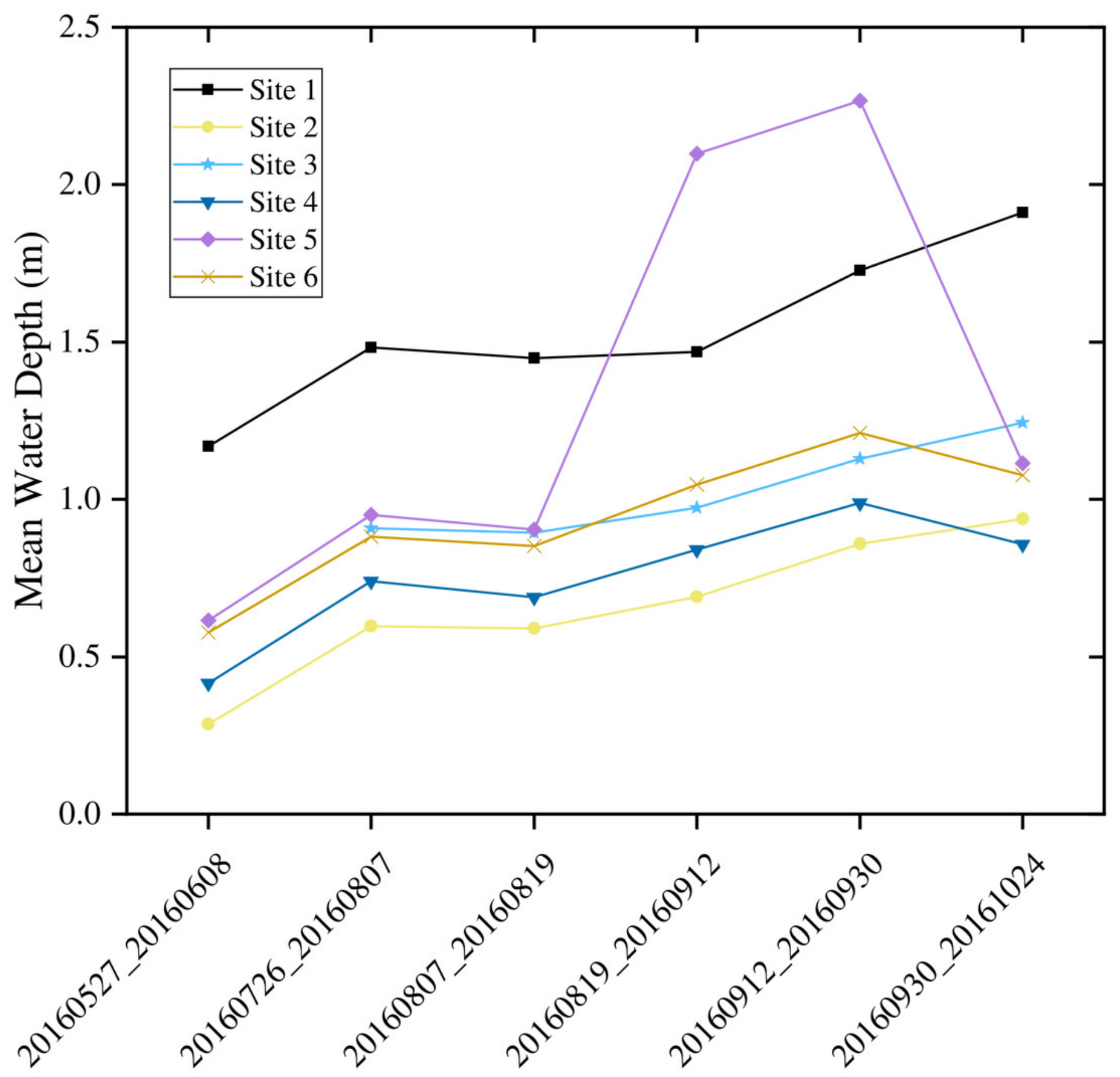


Figure 9

Relation between mean interferometric coherence and mean SAR backscatter for stable areas of the marsh wetlands in the Momoge National Nature Reserve, Northeast China with the Sentinel-1 data.

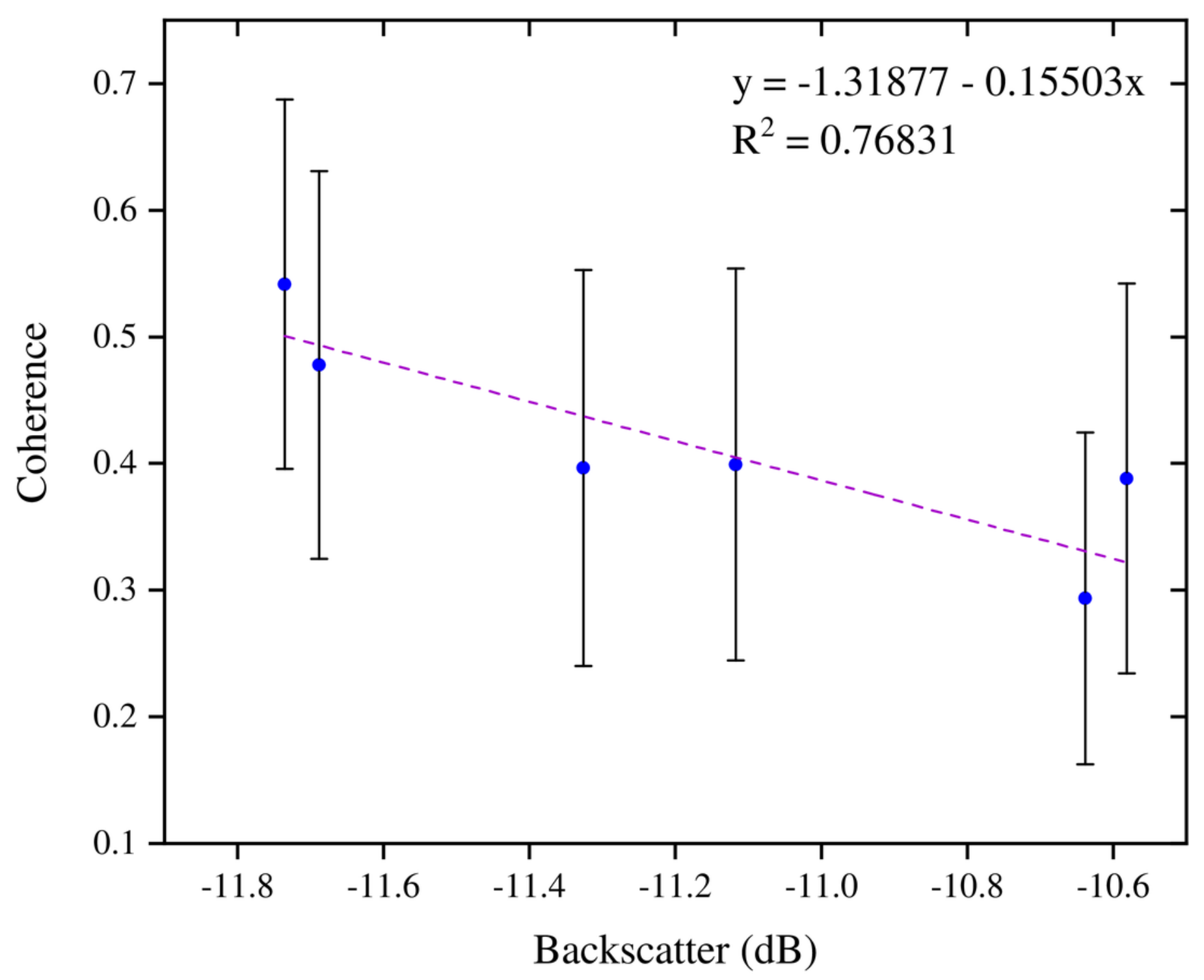




\section{Figure 10}

Interferograms of phase changes in the Momoge National Nature Reserve, Northeast China. Each interferometric pair has a short temporal baseline as no more than 24 days.

Data source: https://scihub.copernicus.eu/ 


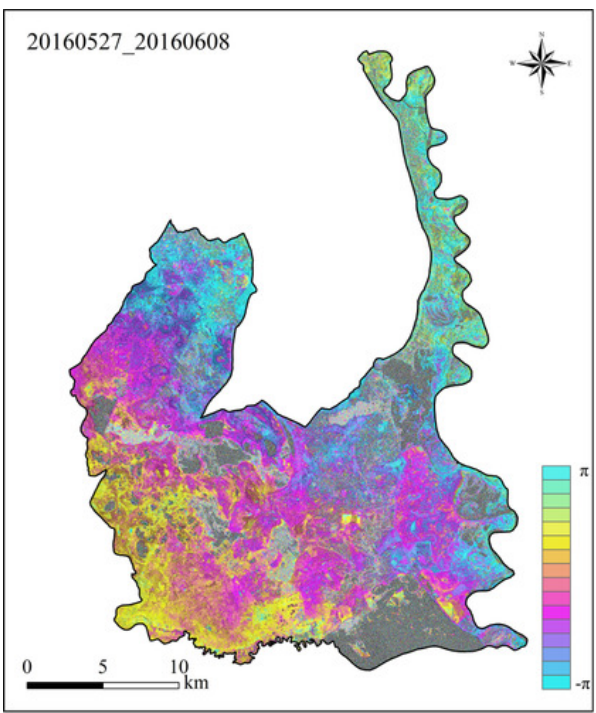

(a)

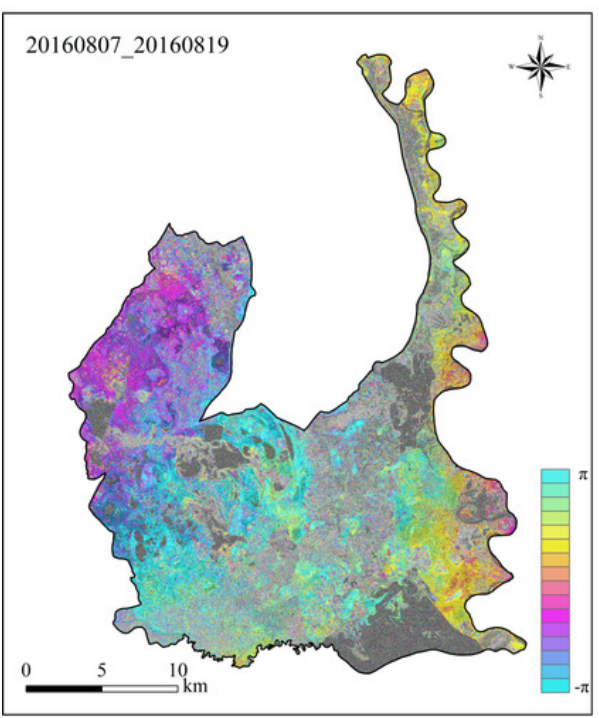

(c)

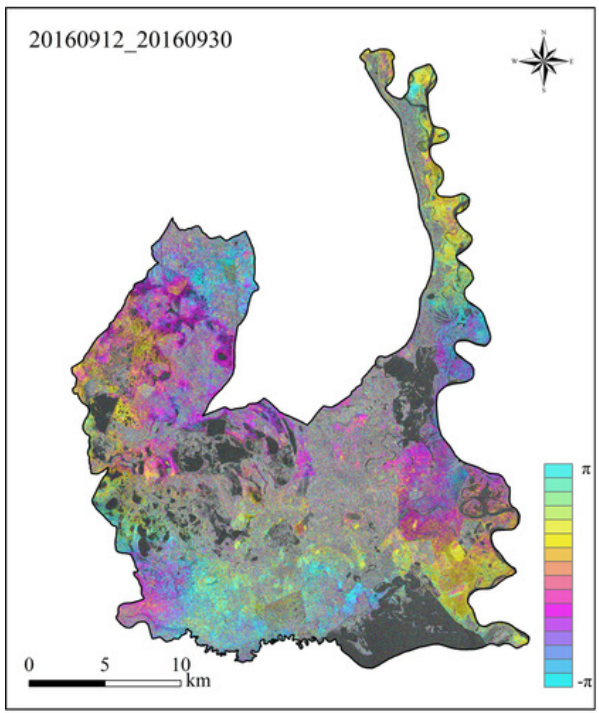

(e)

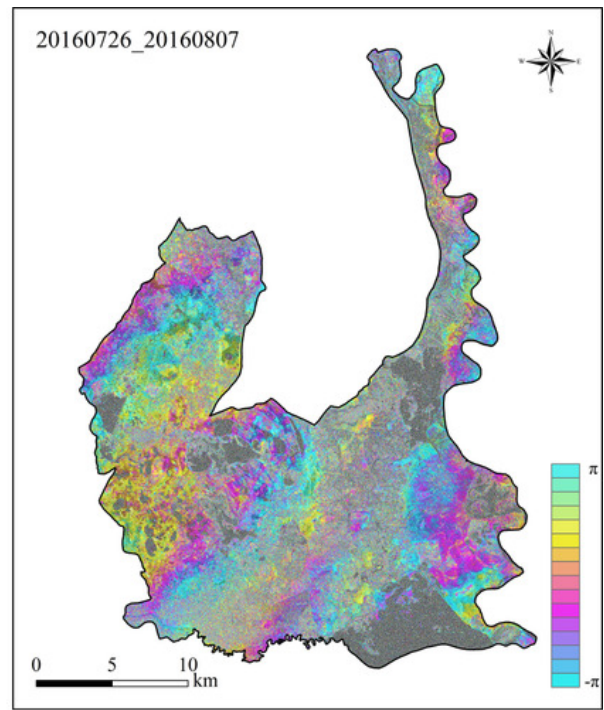

(b)

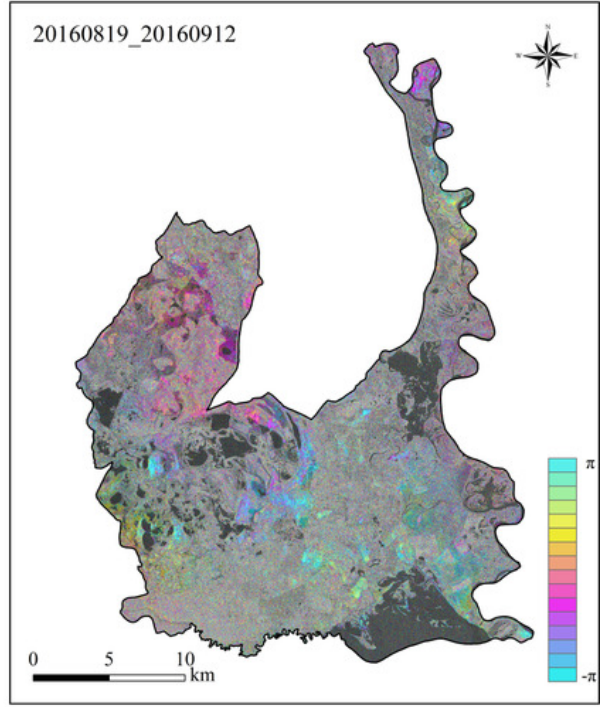

(d)

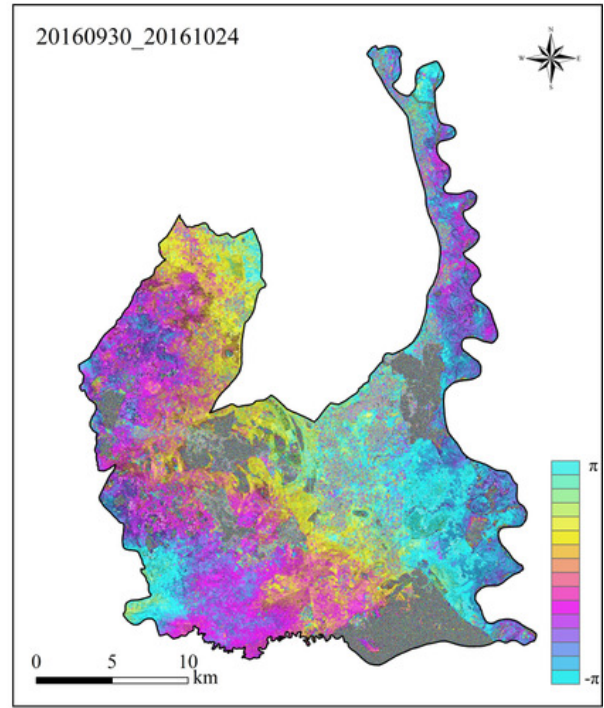

(f) 


\section{Figure 11}

Calibration plots for estimating the offsets between InSAR observations and logger observations for

(a) all interferometric pairs in relatively shallow flooding marsh wetlands (water depth lower than $1 \mathrm{~m}$ ); (b) all interferometric pairs in relatively deep flooding marsh wetlands (water depth higher than $1 \mathrm{~m}$ ); and (c) the interferometric pair of July 26, 2016 and August 07, 2016 in relatively shallow flooding marsh wetlands (water depth lower than $1 \mathrm{~m}$ ). The symbol " + " marks outliers that are omitted from the calibration offset calculations. 


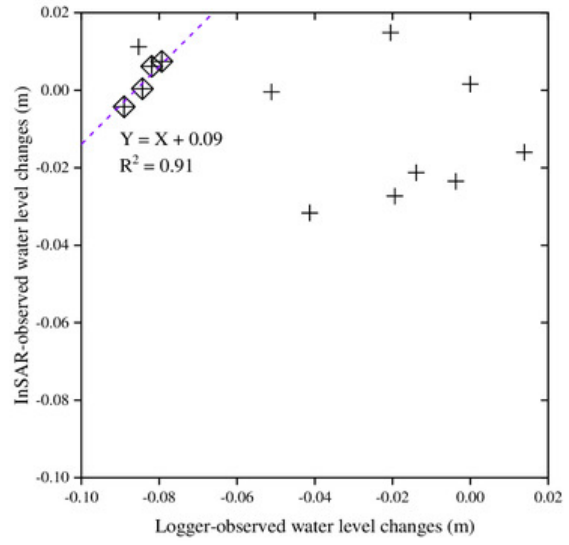

(a)

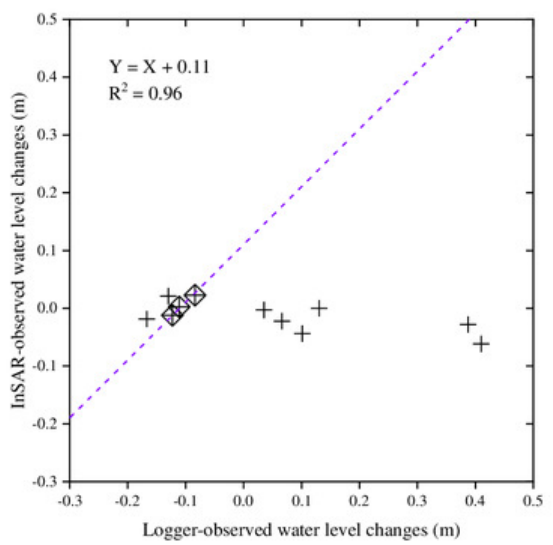

(b)

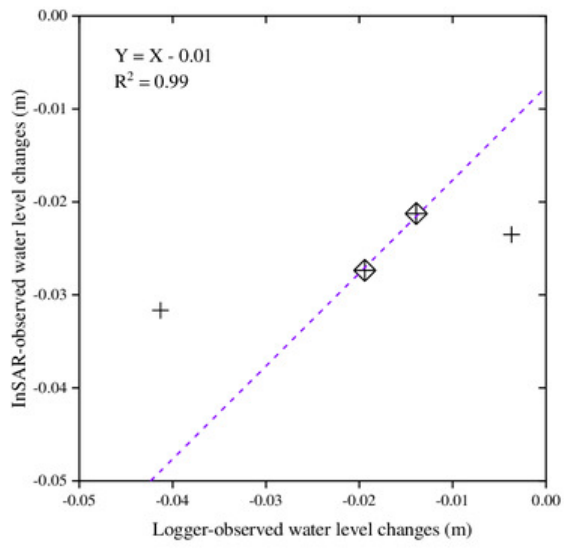

(c) 
Figure 12

Mean interferometric coherence of the marsh wetlands. The x-axis shows the six interferometric pairs with a short temporal baseline as no more than 24 days.

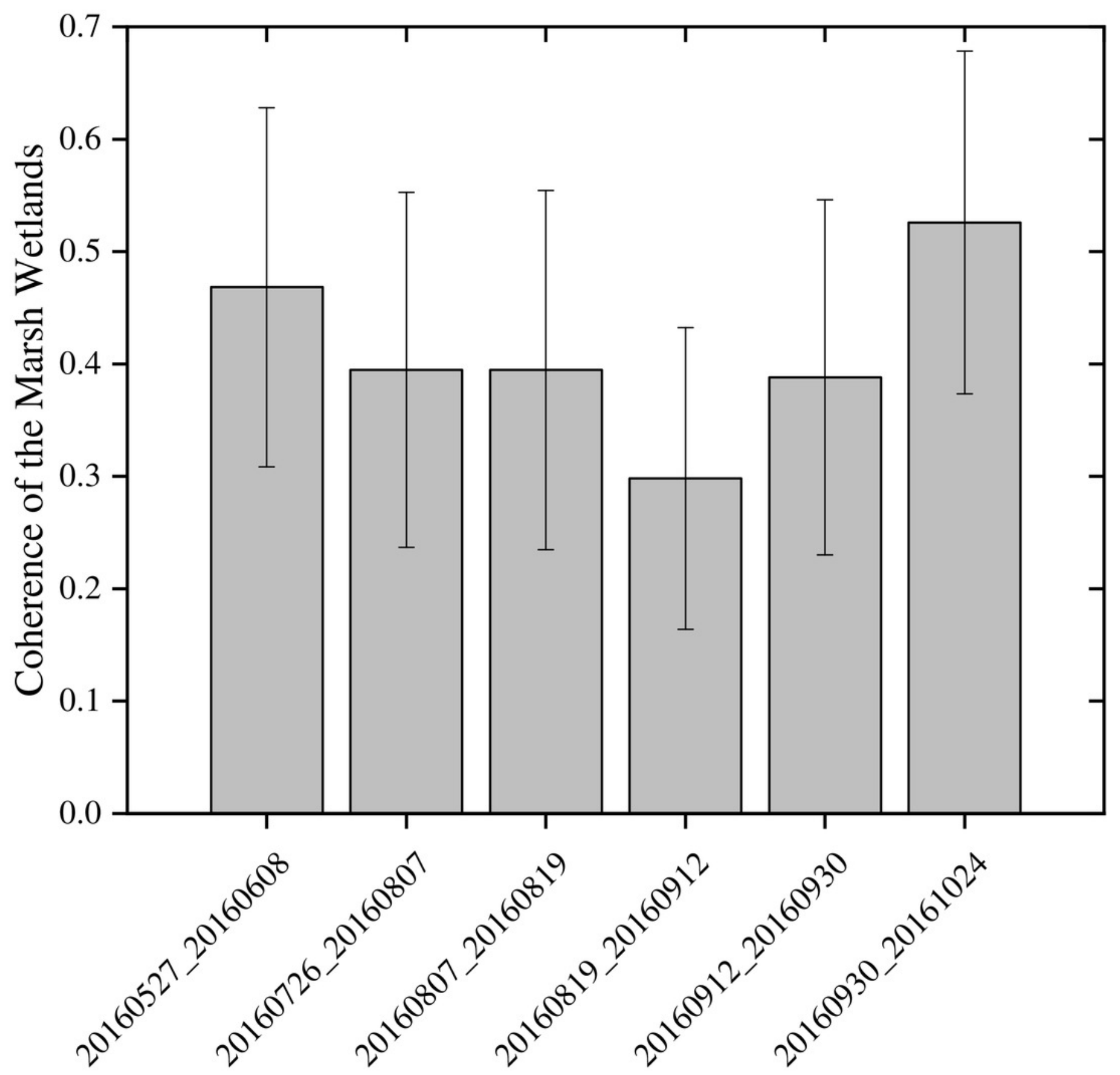




\section{Table 1 (on next page)}

Number of ROIs and pixels in each class type used for training the MLC classifier. 


\begin{tabular}{lllllllll}
\hline & Marsh & Water & Ditch & Dam & Cropland & Forest & Residential & $\begin{array}{l}\text { Saline } \\
\text { Soil }\end{array}$ \\
\hline $\begin{array}{l}\text { Number of } \\
\text { ROIs }\end{array}$ & 198 & 197 & 48 & 52 & 187 & 156 & 82 & 138 \\
$\begin{array}{l}\text { Number of } \\
\text { Pixels }\end{array}$ & 5781 & 6672 & 553 & 589 & 3274 & 4681 & 2780 & 3810 \\
\hline
\end{tabular}

1 
Table 2 (on next page)

Summary of confusion matrix. 


\begin{tabular}{|c|c|c|c|c|c|c|c|c|c|}
\hline & & \multicolumn{8}{|c|}{ Reference Data } \\
\hline & & $\begin{array}{l}\text { Mars } \\
\text { h }\end{array}$ & $\begin{array}{l}\text { Wate } \\
\text { r }\end{array}$ & $\begin{array}{l}\text { Ditc } \\
\text { h }\end{array}$ & $\begin{array}{l}\text { Da } \\
\text { m }\end{array}$ & $\begin{array}{l}\text { Croplan } \\
\text { d }\end{array}$ & $\begin{array}{l}\text { Fore } \\
\text { st }\end{array}$ & $\begin{array}{l}\text { Residenti } \\
\text { al }\end{array}$ & $\begin{array}{l}\text { Salin } \\
\text { e } \\
\text { Soil }\end{array}$ \\
\hline \multirow{9}{*}{$\begin{array}{l}\text { Classifie } \\
\text { d Data }\end{array}$} & Marsh & 23 & 1 & 0 & 0 & 1 & 1 & 0 & 0 \\
\hline & Water & 3 & 33 & 0 & 0 & 1 & 0 & 0 & 3 \\
\hline & Ditch & 0 & 0 & 20 & 0 & 0 & 0 & 0 & 1 \\
\hline & Dam & 0 & 0 & 2 & 18 & 0 & 0 & 0 & 0 \\
\hline & Cropland & 0 & 1 & 0 & 0 & 36 & 2 & 0 & 0 \\
\hline & Forest & 0 & 0 & 0 & 0 & 1 & 21 & 0 & 0 \\
\hline & $\begin{array}{l}\text { Residenti } \\
\text { al }\end{array}$ & 0 & 0 & 0 & 0 & 0 & 1 & 44 & 0 \\
\hline & Saline & 2 & 1 & 0 & 0 & 1 & 0 & 1 & 22 \\
\hline & Soil & & & & & & & & \\
\hline
\end{tabular}




\section{Table 3 (on next page)}

Summary of Accuracy (\%) and Kappa statistics of MLC map. 


\begin{tabular}{|c|c|c|c|c|c|c|c|c|}
\hline $\begin{array}{l}\text { Classificatio } \\
\text { n Metric }\end{array}$ & $\begin{array}{l}\text { Mars } \\
\text { h }\end{array}$ & $\begin{array}{l}\text { Wate } \\
\text { r }\end{array}$ & $\begin{array}{l}\text { Ditc } \\
\text { h }\end{array}$ & Dam & $\begin{array}{l}\text { Croplan } \\
\text { d }\end{array}$ & $\begin{array}{l}\text { Fores } \\
\text { t }\end{array}$ & $\begin{array}{l}\text { Residentia } \\
\text { I }\end{array}$ & $\begin{array}{l}\text { Salin } \\
\text { e Soil }\end{array}$ \\
\hline $\begin{array}{l}\text { Precision } \\
\text { (User's } \\
\text { Accuracy) }\end{array}$ & 88.5 & 82.5 & 95.2 & 90.0 & 92.3 & 95.5 & 97.8 & 81.5 \\
\hline $\begin{array}{l}\text { Recall } \\
\text { (Producer's } \\
\text { Accuracy) }\end{array}$ & 82.1 & 91.7 & 90.9 & $\begin{array}{l}100 . \\
0\end{array}$ & 90.0 & 84.0 & 97.8 & 84.6 \\
\hline $\mathrm{F} 1$ & 85.2 & 86.8 & 93.0 & 94.7 & 91.1 & 89.4 & 97.8 & 83.0 \\
\hline $\begin{array}{l}\text { Overall } \\
\text { Accuracy }\end{array}$ & 90.4 & & & & & & & \\
\hline $\begin{array}{l}\text { Kappa } \\
\text { Statistics }\end{array}$ & 88.9 & & & & & & & \\
\hline
\end{tabular}

